\title{
Microbial Efflux Systems and Inhibitors: Approaches to Drug Discovery and the Challenge of Clinical Implementation
}

\author{
Christina Kourtesi ${ }^{1,2}$, Anthony R. Ball ${ }^{3}$, Ying-Ying Huang ${ }^{4,5}$, Sanjay M. Jachak ${ }^{6}$, D. Mariano A. \\ Vera $^{7}$, Proma Khondkar ${ }^{8}$ Simon Gibbons $^{8}$, Michael R Hamblin ${ }^{4,5,9}$, and George P. Tegos ${ }^{*, 1,4,5,10}$ \\ ${ }^{1}$ Department of Pathology, University of New Mexico, School of Medicine, Albuquerque, NM, USA \\ ${ }^{2}$ Department of Pathology, Faculty of Medicine, National \& Kapodistrian University of Athens, Greece \\ ${ }^{3}$ Department of Microbiology, Toxikon Corp. Bedford, MA 01730, USA \\ ${ }^{4}$ Department of Dermatology, Harvard Medical School, Boston MA, USA \\ ${ }^{5}$ Wellman Center for Photomedicine, Massachusetts General Hospital, Boston MA, USA \\ ${ }^{6}$ Department of Natural Products, National Institute of Pharmaceutical Education and Research, Sector-67, SAS Nagar, \\ Punjab, India \\ ${ }^{7}$ Department of Chemistry, Facultad de Ciencias Exactas y Naturales, Universidad Nacional de Mar del Plata, 3350 - \\ 7600- Mar del Plata, Argentina \\ ${ }^{8}$ Department of Pharmaceutical and Biological Chemistry, UCL School of Pharmacy, London WC1N 1AX, UK \\ ${ }^{9}$ Harvard-MIT Division of Health Sciences and Technology, Cambridge, MA, USA \\ ${ }^{10}$ Center for Molecular Discovery, University of New Mexico, Albuquerque, NM 87131, USA
}

\begin{abstract}
Conventional antimicrobials are increasingly ineffective due to the emergence of multidrug-resistance among pathogenic microorganisms. The need to overcome these deficiencies has triggered exploration for novel and unconventional approaches to controlling microbial infections. Multidrug efflux systems (MES) have been a profound obstacle in the successful deployment of antimicrobials. The discovery of small molecule efflux system blockers has been an active and rapidly expanding research discipline. A major theme in this platform involves efflux pump inhibitors (EPIs) from natural sources. The discovery methodologies and the available number of natural EPI-chemotypes are increasing. Advances in our understanding of microbial physiology have shed light on a series of pathways and phenotypes where the role of efflux systems is pivotal. Complementing existing antimicrobial discovery platforms such as photodynamic therapy (PDT) with efflux inhibition is a subject under investigation. This core information is a stepping stone in the challenge of highlighting an effective drug development path for EPIs since the puzzle of clinical implementation remains unsolved. This review summarizes advances in the path of EPI discovery, discusses potential avenues of EPI implementation and development, and underlines the need for highly informative and comprehensive translational approaches.
\end{abstract}

Keywords: Antimicrobial resistance, multidrug efflux systems, natural efflux pump inhibitors, photo inactivation, dual action antimicrobials, biofilms, virulence.

\section{INTRODUCTION}

The $20^{\text {th }}$ century gave rise to many successful methods for preventing and controlling infectious diseases but fostered the mindset that the war against infectious microbes was over. In the 1980s consensus among pharmaceutical companies was that there were enough antibiotics already on the shelf and research efforts were redirected elsewhere [1].

*Address correspondence to this author at the Department of Pathology School of Medicine \& Center for Molecular Discovery University of New Mexico, UNM Health Sciences Center 2325 Camino de Salud, CRF 217A MSC 07-4025 Albuquerque, NM 87131, USA; Tel: 505-272-1608;

Fax: 505-272-6995; E-mail: gtegos@salud.unm.edu
Optimism was short-lived however when outbreaks and epidemics of new, re-emerging, and drug-resistant infections arose. Termed "superbugs", emergent microorganisms possessing effective and dynamic pathogenic capabilities continue to be a dangerous threat. Each year over 13 million deaths worldwide are attributed to the emergence of new infectious diseases or to the re-emergence of diseases previously thought well-controlled.

One major component of resistance to many classes of antimicrobials as well as chemotherapeutic agents is multidrug efflux [2]. Efflux results from the activity of membrane transporter proteins known as multidrug efflux sys- 
tems (MES) [3, 4]. MES perform essential roles in cellular metabolism and differ in membrane topology, energy coupling mechanisms, and, most importantly, substrate specificities [5]. Identifying natural substrates and inhibitors of efflux systems is an active and expanding research topic [6]. Based on their sequence similarity, efflux systems have been classified into the following six super-families (Fig. 1): ATP-binding cassettes (ABC), Multidrug and Toxic compound efflux (MATE), resistance-nodulation cell division (RND), small multidrug resistance family (SMR), multiantimicrobial extrusion protein family, and multidrug endosomal transporters (MET). The first five families are found in microorganisms while the MET family appears restricted to higher eukaryotes. Representatives of all groups are expressed in mammalian cells [7]. ABC transporters are the largest super family, containing seven subfamilies designated $\mathrm{A}$ to $\mathrm{G}$ based on sequence and structural homology [8].

The molecular mechanism of the transporter substrate recognition, the kinetics, the stoichiometry and the features of the antiport process, is an ongoing field of investigation. Structural studies indicate that the transporters may capture their substrates directly from the periplasm or from the outer leaflet of the cytoplasmic membrane $[9,10]$. In retrospective, the key steps of drug transport involve several and specific interplays between intramolecular and intermolecular conformational changes and intermolecular dynamics; It will be impossible to dissect without a coordinated effort that involves crystallography, molecular modeling, molecular biology, energy calculation and biological-functional investigations. The scenario is more complicated since some drug transporters show a cooperative interaction or can act sequentially $[11,12]$.

A fundamental challenge associated with drug transport both for RNDs and ABCs efflux systems independently of the mechanistic differences between antiport and energy dependent efflux is associated is the broad specificity (or poly-specificity). It is very difficult to distinguish between a 'single' binding step and a correct recognition binding inside the high-affinity pocket with an active conformation, allowing efficient translocation of the drug to the outer membrane channel. The structural data including molecular docking calculations have provided some information [13], but they are rather far from model development without biological support $[14,15]$. The energy source is a key element of transport function and substrate recognition as for at least the proton antiporters efflux is a $\mathrm{pH}-$ dependent process [16]. This is also an active field of investigation in a variety of pathogens $[17,18]$.

In order to address the obstacles of efflux to chemotherapy, an array of approaches have been investigated i) Bypassing efflux systems by improving the molecular design of old antibiotics in order to reduce their efflux. ii) Decreasing the efficacy of the membrane barrier by a direct modification or a channel-blocker that induces a 'traffic jam' in the outer membrane channel restoring a high intracellular drug concentration. iii) Blocking the efflux capacity of microbial cells through competitive, non-competitive inhibition as well as direct or indirect energy depletion via an anti-porter site or via a collapse of energy driven mechanisms of the microbial cell envelope.

Natural products play a major role in drug discovery by providing bioactive scaffolds with activity against a variety of targets in infections and cancer. The strategy of efflux system inhibition employing natural product efflux pump inhibitors (EPIs) emerged in the last decade. Reports for novel and already known natural chemical entities which are active against virtually all of the major microbial efflux systems have populated the chemical space as well as the literature $[6,19]$. The concept of restoring and enhancing the utility of antimicrobials by employing EPIs is appealing but is not yet at a therapeutic stage. Discovery efforts are multidimensional and continuously expanding but a number of conceptual and methodological gaps are barring identification of lead EPIs for clinical implementation. This review summa-

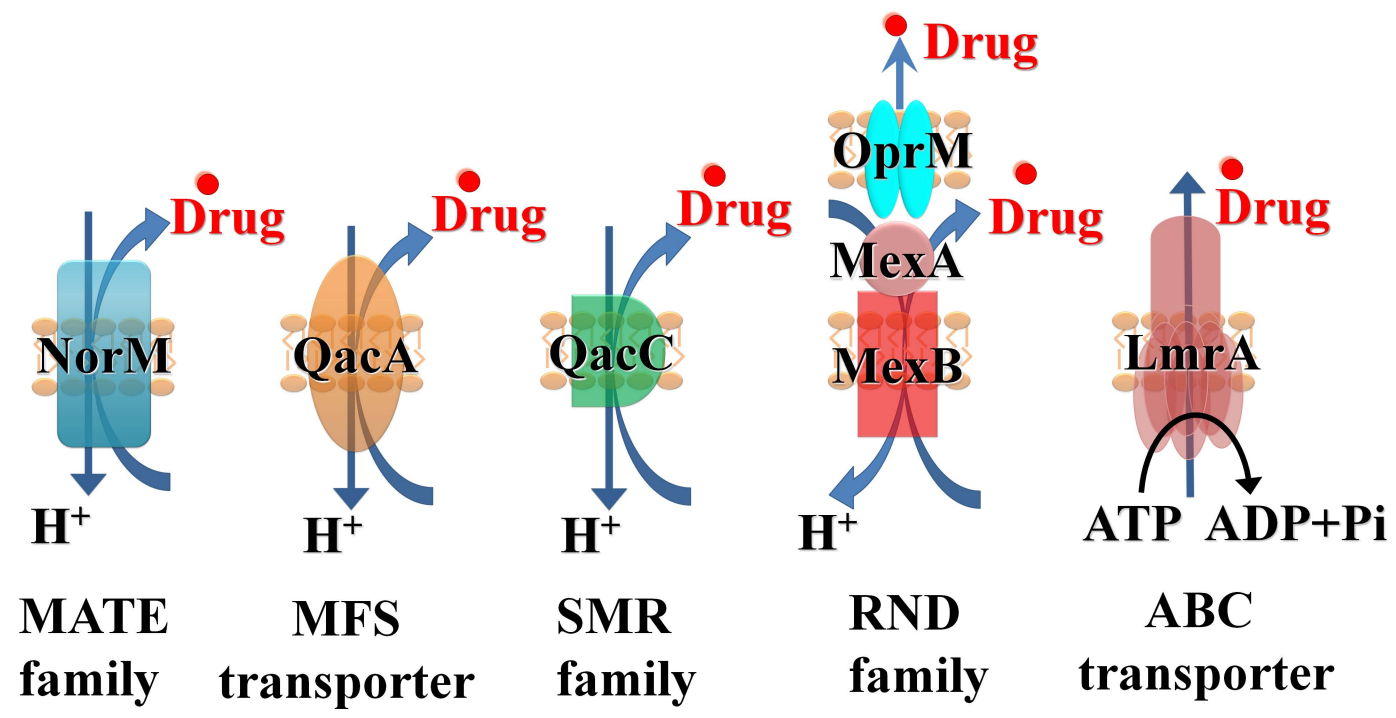

Fig. (1). Schematic illustration for key members of the 5 super-families of the microbial efflux systems: NorM, multi-antimicrobial extrusion protein family (MATE), QacA major facilitators (MFS), QacC small multidrug resistance family (SMR), MexAB, resistance-nodulation cell division (RND), LmrA, ATP-binding cassettes (ABC). 
rizes the tools for EPI discovery and validation with emphasis on those of plant origin. The path forward towards development and deployment in a clinical setting is also outlined.

\section{MES in Gram-positive Bacteria}

The major efflux systems implicated in Gram-positive bacterial related drug resistance are the chromosomally encoded MFS Nor-family (NorA, NorB, NorC), MdeA the MATE mepRAB (multidrug export protein) [20] and the SMR SepA [21]. There is also evidence for plasmid encoded systems such as QacA, QacB, [22,23] and Tet(K) that function as tetracycline-divalent metal complex $/ \mathrm{H}^{+}$antiporters [24]. A NorA homolog (EmeA) has also been validated in Enterococcus faecalis [25]. These systems have a broad and overlapping substrate specificity including quinolones, tetracyclines, monovalent and divalent antimicrobial cations (intercalating dyes, quaternary ammonium compounds, diamidines, biguanidines) and plant secondary metabolites $[26$, 27].

\section{MES in Gram-negative Bacteria}

Multidrug-resistant (MDR) and pandrug-resistant (PDR) Gram-negative bacteria, pose a grave threat of truly untreatable infections [28,29]. Efflux systems are key players in a variety of challenging clinical conditions. The resistance nodulation cell division (RND) family includes protondriven systems with key members the AcrAB-TolC in E. coli with strong homology in Francisella tularensis, Yersinia pestis, and Brucella sp. AcrB functions as a multi-subunit complex in association with the outer membrane channel TolC and the membrane fusion protein AcrA. There are 12 RND-type efflux systems present in Pseudomonas aeruginosa of which three, MexAB-OprM, MexCD-OprJ, and MexXY-OprM have been shown to accommodate and provide resistance to $\beta$-lactams and fluoroquinolones (with the addition of MexEF-oprN) [30]. The partition of efflux in the resistance related to aminoglycosides, antimicrobial peptides and biofilm formation is established but is part of a more sophisticated cell response [30]. The characteristics of additional RND-type systems such as MexABC-OpmB [31] and TriABC-OpmH, a triclosan efflux pump, have been recently dissected [32]. The mex-locci in P. aeruginosa are phylogenetically related with a set of homologues systems in 3 key pathogens:

1. The 11 Bpe-efflux systems in Bulkhoderia pseudomallei, and B. mallei [33]. BpeAB-OprB is a broad-spectrum MES which is only expressed at low levels and only marginally contributes to multidrug resistance (MDR). In contrast, strains expressing BpeEF-OprC are highly resistant to most of the clinically useful antibiotics for melioidosis treatment.

2. The 16 RND efflux systems present in B. cenocepacia (Bcc complex, RND-1 to -16) [34] and bmeABC1-16 in the Bacteroides fragilis [35]. At least seven BmeB efflux pumps are functional in transporting antimicrobials and have overlapping substrate profiles, and at least four confer intrinsic resistance [35].

3. At least 5 ade RND systems have been fully functionally characterized in Acinetobacter baumannii including AdeIJK [36] adeSR-adeABC, adeDE [37] and AdeFGH [38].
$A B C$ efflux systems have been identified in several occasions including the heterodimeric SmdAB in Serratia marcescens [39] and the E. coli macrolide transporter MacAB [40]. The later has been also validated in Neisseria gonorrhoeae [41].

A number of MFS with efflux capabilities are present in Gram-negative bacteria. This list includes the Salmonella enterica sv. Typhimurium SmvA, most similar to QacA of $S$. aureus [42], the EmrAB-TolC in E. coli [43], and the QepA and OqxAB plasmids involved in quinolone resistance in $E$. coli and Klebsiella spp. [44] but with a wide distribution in Enterobacteriaceae. CraA in A. baumannii is homologous to the MdfA of $E$. coli, which extrudes only chloramphenicol and the acquired narrow-spectrum systems TetA, TetB, CmlA, and FloR [45]. AmvA, mediates antimicrobial and disinfectant resistance in A. baumannii [46]. Members of the SMR and MATE families have been detected in a variety of Gram-negative bacterial species. AbeM and AbeS have been characterized in A. baumannii, as have AdeXYZ, AdeDE and QacE for other Acinetobacter spp. [45]. SugE, contributes to antimicrobial resistance in Enterobacter cloacae [47].

\section{MES in Mycobacteria}

The Mycobacterial complex possesses a remarkable variety of efflux systems which are either members of the MFS or ABC super families. Mycobacterium tuberculosis presents one of the largest numbers of putative drug efflux pumps compared with its genome size. Bioinformatics as well as direct and indirect evidence have established relationships among drug efflux with intrinsic or acquired resistance in $M$. tuberculosis [48]. Tap is the first MFS system identified (Rv1258 in the annotated sequence of the M. tuberculosis genome) [49]. Genome analysis and homology search between the identified transporters and proteins characterized in other organisms have revealed 16 open reading frames encoding putative drug efflux pumps belonging to the MFS. The efflux function has been demonstrated in at least three of these including the sequence Rv0849. [50,51]. The list is expanding to include ABC Superfamily members such as DrrAB [52] Bcg0231 (M. bovis BCG) Rv0194 [53] Rv1218c[51] Rv1456c-Rv1457c-Rv1458c [54] and the SMR systems Rv3065 [51] LfrA in M. smegmatis [55] as well as the homologues of $M$. tuberculosis Rv1145, Rv1146, Rv1877, Rv2846c (efpA), [56] and Rv3065 (mmr and emrE) in both $M$. tuberculosis and M. smegmatis [57].

\section{MES in Fungi}

The best-studied families of fungal MES are from Saccharomyces cerevisiae, especially those responsible for pleiotropic drug resistance (PDR) [58]. Members of this family are highly conserved and are often responsible for drugresistance among pathogenic fungal species [59]. Although fungal cells contain many genes for both types of systems, clinical azole resistance is most often associated with overexpression of $\mathrm{ABC}$ transporters [60]. Clinically important PDR transporters include C. albicans Cdrlp (CaCdrlp) and $\mathrm{CaCdr} 2 \mathrm{p}$, which are homologs of the $S$. cerevisiae Pdr5p (ScPdr5p) and mammalian G-type ABC transporters [60-62]. Fungal PDR efflux systems have relatively promiscuous substrate specificities that are presumably defined by their 
transmembrane domains. Analysis of the C. albicans genome has identified several efflux pumps (CDR1, CDR2, CDR3, CDR4, CDR5, SNQ2, and YOR1) belonging to the $\mathrm{ABC}$ superfamily.

\section{Role of MES in Antimicrobial PDT}

Given the broad spectrum of multidrug efflux pumps to raise resistance against various antibiotics and antimicrobials, an unconventional antimicrobial discovery effort is needed [1]. Photodynamic therapy (PDT), is a light-based technology platform [63], which uses harmless visible light in combination with non-toxic photosensitizers (PS) to control infections (Fig. 2). Historically PDT has had a prominent role in the cancer therapeutics and is also currently used to treat age-related macular degeneration [64]. Currently PDT is being investigated as an alternative treatment for localized infections [65]. PSs are usually organic aromatic molecules with a high degree of electron delocalization [66]. Porphyrins, chlorins, bacteriochlorins, phthalocyanines as well as a plethora of dyes with different molecular frameworks have been proposed as antimicrobial PSs $[67,68]$. These dyes include halogenated xanthenes (e.g. Rose Bengal (RB), [69] perylenequinones (e.g. hypericin), phenothiazinium dyes
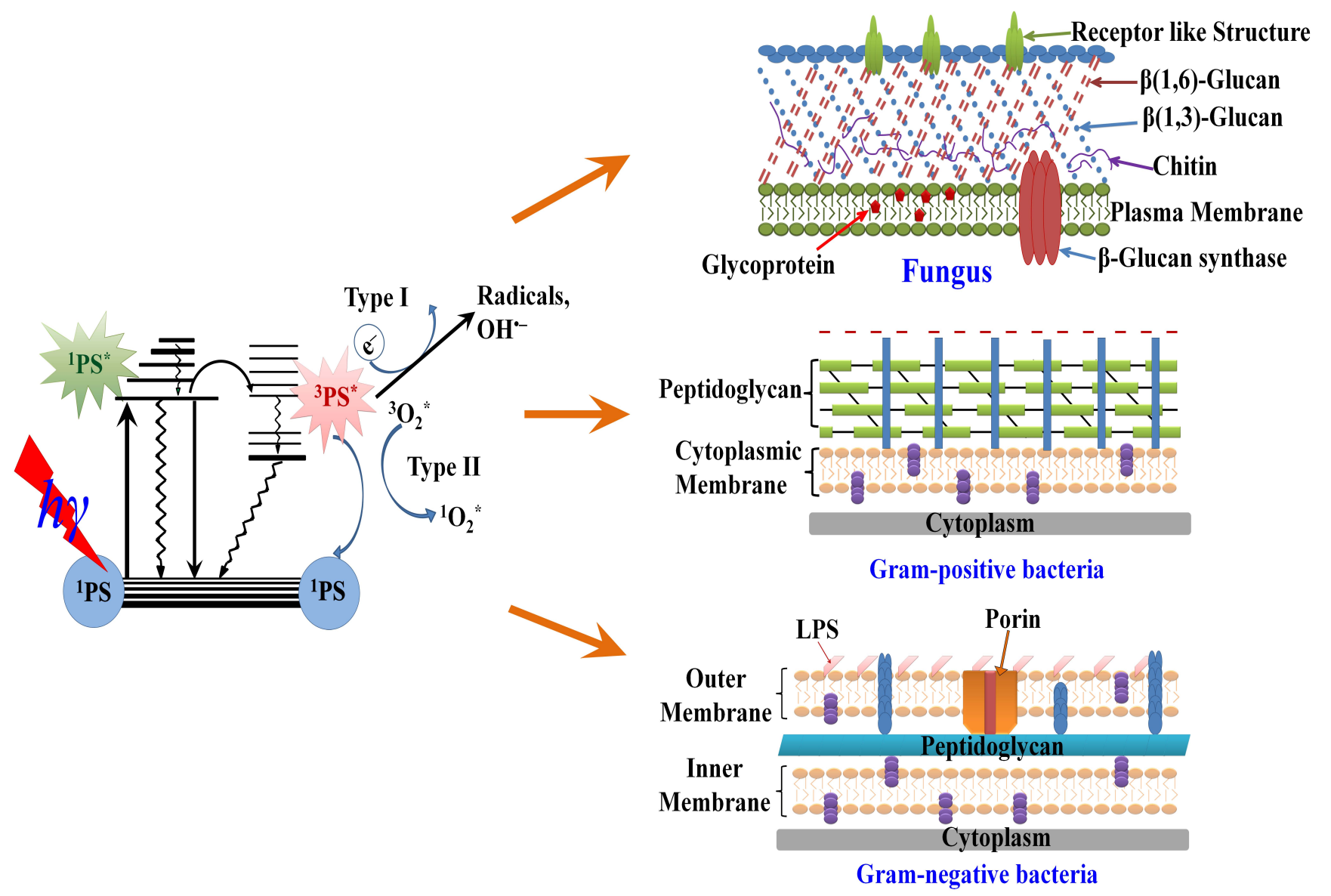

such as methylene Blue (MB) and toluodine blue (TBO) [70], cationic fullerenes (e.g. derivatives of $\mathrm{C}_{60}$ ), [71,72] and psoralens (e.g. furanocoumarins) [73].

PDT is quite different in comparison with conventional drug discovery platforms, since three elements (PS, visible light and oxygen) are essential for successful deployment. One of the main challenges for the rational design of efficient PSs arise precisely from the fact that the electronically excited states (singlet, triplet and reactive intermediates) of the photoactive agent causes cell toxicity $[74,75]$. This prompts the use of complex, computing-demanding high level Quantum Chemistry approaches for dealing with excited states [76-81]. Such in silico modeling, in combination with photophysical experimental studies are required for rationally tuning the desired properties of the PSs including dark toxicity, molar absorption coefficient, absorption wavelength, singlet-triplet intersystem crossing quantum yield and forthcoming singlet oxygen generation and probably also the study of open sheel species (radical cations in case of phototoxicity in the absence of oxygen) [82-84]. Examples from these interdisciplinary efforts yielded chemical modifications to enhance known dyes, as well as the re-consideration of dyes which absorb outside the desirable wavelength window

Fig. (2). Schematic illustration for: the mechanism of photodynamic inactivation including the Jablonski diagram (left) and the microbial permeability barriers of Gram-positive, Gram-negative bacteria and fungi (right). The PS initially absorbs a photon that excites it to the first excited singlet state and this can relax to the more long lived triplet state. This triplet PS can interact with molecular oxygen in two pathways, type I and type II, leading to the formation of reactive oxygen species (ROS) and singlet oxygen respectively. 
(600-850 $\mathrm{nm}$ ) by means of two-photon absorption [83-85] of yellow-orange dyes by means of potent red lasers, as well as the preparation of either highly positively charged derivatives [86] or conjugates of the PS and antibodies or nanoparticles for improving their specificity and/or cell accumulation [87-89].

Many of the elements of the bacterial phenotype may play an important role as PDT applications evolve. A set of technical challenges will have to be met using sophisticated tools and approaches that address complex biological questions regarding resistance mechanisms, biofilm inactivation, and persister cell formation. There are no validated examples of biofilm photoinactivation or PDT being used in reliable polymicrobial infection models. Minimal information exists for the design of host-pathogen studies exploring the ability of PDT to interfere with virulence determinants, although there is one notable exception; a report of a host-parasite model to assess intracellular targeting specificity of novel phthalocyanines against Leishmania parasites infecting macrophages and dendritic cells [90]. However the nonspecific mechanism of action and successful clinical implementation prompt and direct a growing critical mass of antimicrobial PDT explorations.

The participation of efflux systems in PS mediated PDT has been observed with the $\mathrm{ABC}$ mammalian transporters ABCG2 (or Breast Cancer Resistance Protein BCRP), $\mathrm{ABCC} 1$ (or multidrug resistance-associated protein 1, MRP1) and in a lesser extent with ABCB1 (P-glycoprotein, P-gp). Primary evidence came from a variety of PDT investigations with porphyrins (phytoporphyrin, protoporphyrin IX) [91-93], pyropheophorbides and purpurinimides [94]. Both $A B G 2$ and $A B C C 1$ affected the outcome of hypericinmediated PDT in HT-29 adenocarcinoma cells [95]. In these two systems it is clear that MES affect PDT for a variety of PS chemotypes. In contrast, for ABCB1 the evidence for PS substrates (chlorine e6 and psoralen) is sporadic and contradictory [96, 97]. In one only occasion, a hypericinmitoxantrone (MTZ) cocktail plus illumination with blue light potentiated cytotoxicity in bladder and breast cancer cells that overexpress P-gp [98].
The two phenothiazinium dyes MB and TBO are amphipathic cations and physicochemically similar to the natural product antibacterial alkaloid berberine, a well-characterized substrate of MFS efflux systems in Gram-positive bacteria $[27,99]$. This has raised the possibility that phenothiazinium PSs are substrates of microbial efflux systems. Experimental evidence indicated that phenothiaziniums were NorA (MFS) substrates in S. aureus and possibly MexAB (RND) substrates in $P$. aeruginosa [100]. Contrarily this evidence was not supported by a model study using sixty clinical isolates of $P$. aeruginosa overexpressing efflux systems where it was demonstrated that antibiotic-resistant $P$. aeruginosa was as susceptible to TBO-mediated PDI as susceptible strains [101]. The observation that $A B C$ transporters and not MFS transporters affect MB-mediated PDT in the pathogenic yeast Candida albicans is perplexing [100, 102]. An in silico modeling venture, employing $\mathrm{MB}$ and the $\mathrm{ABCB} 1$ crystal structure adds in this perplexity. The study reveals a strong overlap for the PS binding site with the classic efflux substrates berberine and rhodamine $6 \mathrm{G}$ due to similarity in shape and electronic distribution (Fig. 3). It was concluded that $\mathrm{MB}$ appears to be at least as well substrate of $\mathrm{ABCB} 1$ as berberine and rhodamines [103]. Furthermore, the structurally related phenothiazines thioridazine and chromazine have been characterized as EPIs or functional transporter regulators as opposed to substrates of a variety of pathogen efflux systems [104-106].

The well-documented promiscuity of efflux systems may explain the scattered reports for the role of porphyrins as potential substrates. Porphyrin uptake and efflux seem to be regulated by the TolC system in E coli [107]. In Streptococcus agalactiae, two co-regulated efflux transporters modulate intracellular heme and protoporphyrin IX availability [108]. In contrast the PDT pattern of amphiphilic protoporphyrin diarginate PPArg in a variety of efflux related $S$. aureus strains show no correlation for the PS with MES [109].

\section{Tools for EPI Discovery}

A number of assays to identify EPIs have been developed in the last 15 years. As the knowledge around efflux systems

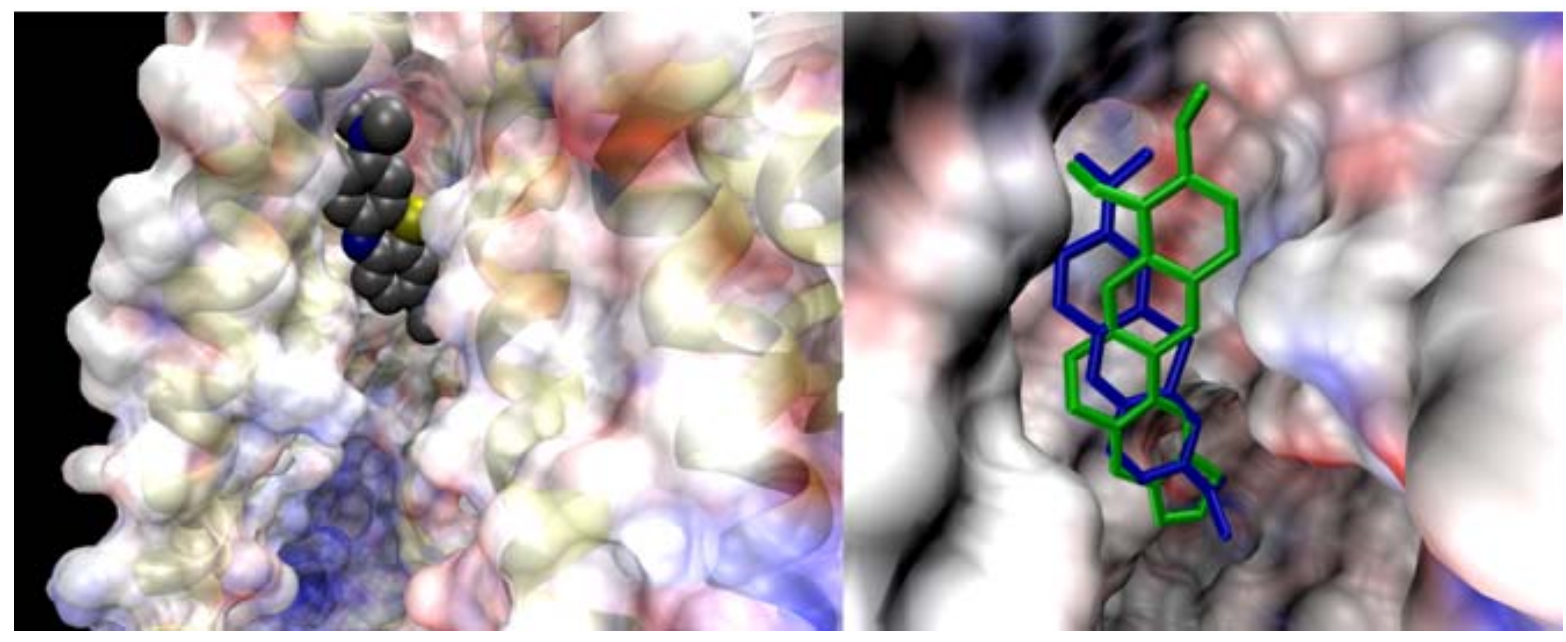

Fig. (3). Left: Methylene blue PS bound to a hydrophobic pocket of an $\mathrm{ABC}$ transporter. The electrostatic potential varies from red (-) to blue $(+)$. Right: The dye (blue tubes) shares the site with berberine (green tubes), a natural antimicrobial and also an ABC substrate. 
is advancing and due to their polyspecificity and overlapping roles in the microbial cell physiology, the majority of the EPI-discovery venture is an evolving "work in progress". The activity of microbial efflux systems is not accurately detected by classical non-functional methods (Northern blotting, RNase protection, RNA in situ hybridization, RT-PCR or immunostaining). Efflux pump protein expression is often not correlated with mRNA levels, as transcripts are often present below the detection threshold, since relatively few active transporter molecules can cause major alterations in drug transport.

One key and generic distinction can be made between functional and phenotypic assays. Both groups of methodologies employ strains that lack or overexpress efflux systems and are usually robust with reproducible results, have been used extensively in low and middle throughput, and are amenable to miniaturization. Computational approaches have also been used but those efforts were not entirely independent as either an assay from the first two categories was coupled to provide proof of principal experimental information. Furthermore, the "on demand" regulation for many efflux systems in the presence of an antimicrobial agent complicates more these expeditions. One of the best understood examples at the molecular level involves the expression of TetA in response of tetracycline/ $\mathrm{Mg}++$ complex, mediated by the TetR transcriptional regulator [110,111] (Fig. 4).

A functional efflux assay is based on the ability of efflux systems to move compounds passively or actively against the concentration gradient, across the cell membrane and on the availability of a variety of fluorescent molecule-dyes to act as substrates of the pump under investigation. Upon loading of the cells with a lipophilic dye capable of diffusing across cell membranes, the fluorescence intensity of the cell will depend upon the activity of the efflux system. The cells, where highly active transporters are present, will display lower fluorescence intensity values because of the increased efflux of the dye/substrate. In the presence of an active EPI, these substrates will accumulate in the cell. The transporter function can be measured in cellular uptake, efflux, or steady-state distribution of fluorescent substrates over time. Two subcategories of functional transporter assays, using fluorescent dyes are commonly employed: i. the accumulation assay measures dye uptake in the presence or absence of known EPIs and ii) the retention assay where the cells are loaded with the substrate in the absence of any modulatorpotential EPI, washed, and then further incubated without dye but in the presence of modulators to allow time for the substrate to be transported out of the cell by the efflux system under investigation. As substrates act differently under different experimental conditions, the distinction between accumulation and retention is essential when evaluating cells for efflux phenotypes. Both assay subcategories offer higher throughput, generic readouts (increase in fluorescence intensity), and are readily automated. As the critical mass and the variety of efflux-based expeditions is increasing, assay development and screening for EPIs have been transferred from conventional fluorimeters and plate readers to fluorescence microscopes and high-resolution multi-parametric flow cytometers.

Acridine orange, berberine, ethidium bromide $(\mathrm{EtBr})$ and rhodamines (6G, and 123) have all been extensively used to report efflux activity in a wide variety of organisms including bacteria and fungi [6]. Recently, by using AcrAB-TolC efflux phenotypes Nile red was validated as a fluorescent dye substrate [112]. Variations of functional assays have been developed through automation to allow evaluation of EPIs against multiple bacterial strains. Classic examples are a) the agar-based method employing EtBr with modifications to evaluate as many as twelve bacterial strains and has been termed the EtBr-agar cartwheel method. Agar plates containing different concentrations of $\mathrm{EtBr}$ are swabbed with bacterial cultures [113] and b) a thermocycler based method for

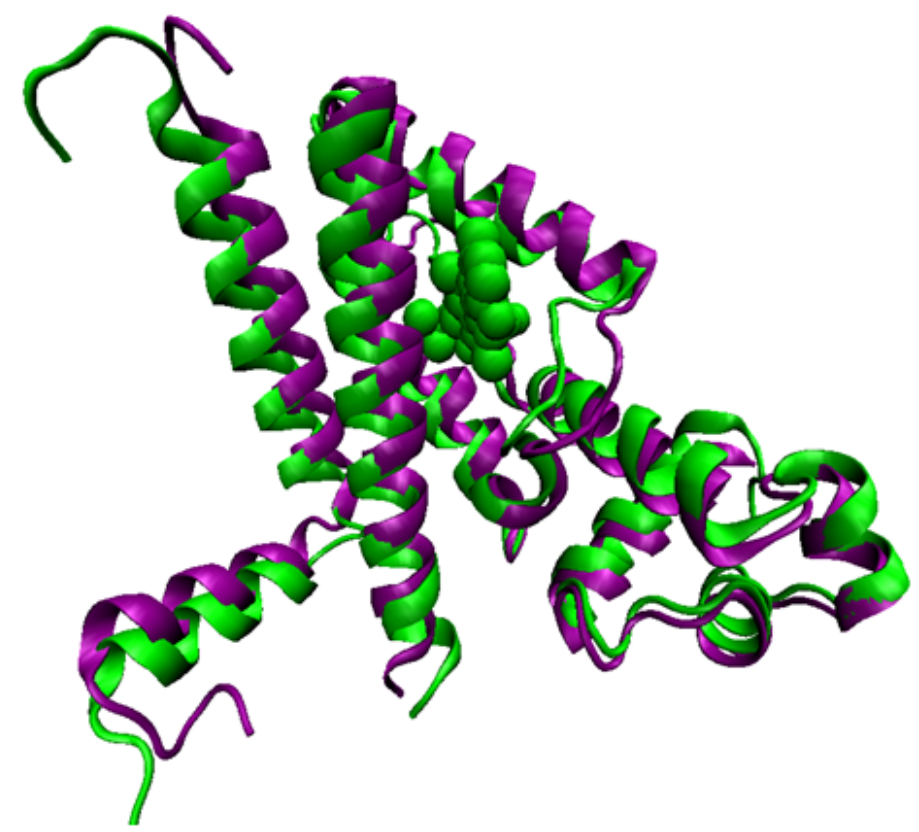

Fig. (4). Structure of the transcriptional repressor TetR in its apo form (violet) and bound to the tetracycline- $\mathrm{Mg}^{2+}$ complex (green); the latter is not competent for binding the TetA MFS promoter; this yielding expression of the MFS just upon antibiotic challenge. 
the real-time assessment of accumulation and efflux of $\mathrm{EtBr}$ under varying physiological conditions (temperature, $\mathrm{pH}$, presence and absence of the energy source) as well as presence of EPIs. The method is sufficiently sensitive to characterize intrinsic efflux systems of multiple reference strains [114].

Unlike mammalian efflux systems, the capabilities of flow cytometry to contribute in microbial EPI discovery have not been extensively explored. In a recent example, an $\mathrm{EtBr}$ flow cytometric efflux assay has been developed to verify the EPI activity of celecoxib, (a cyclooxygenase-2 inhibitor) in S. aureus strains including MRSA and also $M$. smegmatis [115]. EPI activity for the RND efflux systems in E. coli and P. aeruginosa have been monitored using a microfluidic channel device under a fluorescence microscope. Fluorescein-di- $\beta$-D-galactopyranoside (FDG), a fluorogenic compound, is hydrolyzed by $\beta$-galactosidase in the cytoplasm of E. coli to produce a fluorescent dye, fluorescein. Both FDG and fluorescein were found to behave as substrates of E. coli efflux, and employed to validate the microfluidic channel device with two EPIs, the MexB-specific pyridopyrimidine (D13-9001) and non-specific Phe-Arg- $\beta$ naphthylamide (PA $\beta \mathrm{N})$ [116].

In a few occasions uptake using radioactive labeled antibiotics have been used. Uptake of $\left[{ }^{14} \mathrm{C}\right]$ ciprofloxacin verified tariquidar and elacridar as EPIs in S. aureus and elacridar in S. maltophilia [117]. $\left[{ }^{14} \mathrm{C}\right]$ chloramphenicol was employed to identify the EPI activity of an alkylaminoquinazoline in Gram-negative efflux pump-overproducing strains [118].

The phenotypic assays are essentially growth inhibition assays with some modifications. The ultimate goal is to identify whether potential EPI compounds enhance the efficacy of antimicrobials for the interrogated efflux system(s). Growth inhibition of potential EPIs in the presence of substrates in sub-inhibitory concentration have been broadly used in low, middle and high throughput. Checkerboard or matrix assays are the most common and require both compounds (the antimicrobial and the EPI) to be diluted over a concentration range to assess through viability the nature of their interaction. The final readout set up and throughput may vary depending on the viability or imaging method used. The method is straightforward and calculates 1 . The generic modulating factor (MF, fold potentiation of an antimicrobial present at sub-inhibitory concentration $[119,120]$ and 2. The robust Fractional Inhibitory Concentration indices (FICI, distinguishes whether two compounds together are demonstrating additive, synergism or antagonistic activity. FIC indices (FICI) are interpreted as synergic when values are $\geq 4$. The results between synergy and antagonistic tendency are defined as additive or indifferent $[120,121]$.

An EPI targeting proton antiporters should not disrupt the proton motive force. This is clarified through protonophore counter-screen assays that employ for example the accumulation of radiolabeled lactose via the proton motive force (the membrane potential and the $\mathrm{pH}$ gradient) [120]. Independently of the targeting pump an EPI should be stable in potentiating the killing effect of antimicrobials over time. A microbiological time-kill assay is a final in vitro step for the functional characterization of a potential EPI [122]. In a classic example piperine effectively enhanced the bacteri- cidal activity of rifampicin in time-kill studies and also significantly extended its post-antibiotic effect (PAE) [123].

Although the X-ray crystal structures of some transporter families have been reported [124-132] only a limited number of computational methods have been used for microbial EPI identification and validation. Emphasis has been given in MFS and methods are available for the NorA and Rv1258c in M. tuberculosis). The virtual screening procedure employed Fingerprints for Ligands and Proteins (FLAP), a new methodology based on GRID force field descriptors [133] The 3D structure of Rv1258c, using in silico modeling, was analyzed to elucidate the binding of piperine to the active site [123]. Quantitative structure activity relationship [134] has been performed in order to obtain a highly accurate model enabling prediction of inhibition of S. aureus NorA of new chemical entities from natural and synthetic sources. Algorithm based on genetic function approximation method of variable selection in Cerius2 was used to generate the model. The model is not only able to predict the activity of new compounds but also explains the important regions in the molecules in quantitative manner [135].

Examples of Quantitative Structure-Activity Relationships (QSAR) models for prediction of pump inhibitory activity have been employed. The key example involves a model designed with genetic algorithm (GA) and partial least square (PLS) analyses with a good predictive power and yielded the compound 2-(2-Azidomethyl-5-phenoxyphenyl)-5-nitro-1H-indole. The EPI lower the MIC of berberine to $0.091 \mathrm{mg} / \mathrm{L}$ in the $S$. aureus NorA over expression phenotype K2361 [136].

The National Institutes of Health Molecular Libraries Probe Production Centers Network (NIH MLPCN) is tasked with finding small molecule probe compounds for academic facilities and investigators lacking adequate HTS tools to exploit biological systems. The University of New Mexico Center for Molecular Discovery (UNMCMD) has pioneered the development of cell suspension HTS transporter inhibitor discovery assays utilizing a sensitive multiplex flow cytometry platform [137]. The approach incorporates profiling libraries such as the Prestwick Chemical Library (PCL) which consists of 1200 off-patent and known biologically active compounds along with the diverse Molecular Libraries Small Molecule Repository (MLSMR, http://mlsmr.glpg.com/MLSMR_HomePage/) library of greater than 350K compounds. We set out to develop new small molecule scaffolds with distinct efflux inhibition selectivity profiles based on multiplex efflux system target screening. It paved the way for a series of innovations in chemical genetics including novel flow cytometry efflux assays in both mammalian (ABCB1, $\mathrm{ABCB} 6, \mathrm{ABCG} 2, \mathrm{ABCC} 1)$ and yeast transporters including ABC (CDR1, CDR2 in Candida albicans, V-ATPase in Sacharomyces cerevisae) and MFS (MDR1) [138-141].

An HTS campaign was employed based on Nile red or R6G as the fluorescent probes and a phenotypic multiplex (triplex) of heterologous expressed C. albicans transporters in a $S$. cerevisiae system where endogenous efflux systems have been disabled. The PCL HTS campaign led to confirmation of enniatin $B$ as a CDR1 inhibitor and revealed that the monoamine oxidase A inhibitor clorgyline is a broadspectrum inhibitor of fungal $\mathrm{ABC}$ and MFS efflux pump 
activities which reverses the azole resistance of $C$. albicans and Candida glabrata. In a slightly different approach, a target-based functional flow cytometry assay that measures vacuolar $\mathrm{pH}$-dependent fluorescence changes in response to V-ATPase function was developed. The experimental strategy uses the $\mathrm{pH}$-sensitive fluorophore BCECF-AM specific for the yeast vacuole and a potent and highly specific VATPase inhibitor, concanamycin A. The assay was also established by using $\mathrm{pH}$ Luorin, a radiometric $\mathrm{pH}$-sensitive GFP derivative that is used to monitor cytosolic $\mathrm{pH}$.

This approach has been orchestrated as a center driven initiative with ultimate goal to set the foundation for the Transporter-Ligand Interactome. The foundation of the interactome is a UNMCMD predictive tool. This tool is comprised of a database and a visualization component that incorporates data from HTS flow cytometry campaigns with genomics, proteomics, structural informatics and knowledge mining using yeast and mammalian model systems for chemical probe discovery.

\section{EPI Combined with Antibiotics}

The NorA system in S. aureus has been the most prominent discovery target. An array of synthetic efforts has identified a number of chemotypes but there is wealth of structures and information for lead EPIs of natural origin (Table 1). There are numerous antibiotics categorized as first and second line countermeasures to treat TB. According to the WHO report more than 110,000 cases of deaths occur every year and, $\sim 490,000$ cases of MDR to first line TBdrugs, and 40,000 cases of extensively drug resistant (XDR) to first and second line TB-drugs emerge every year [142]. Although resistance to TB is multifactorial, the importance of efflux has been identified and documented in a variety of occasions [51, 143]. A number of synthetic EPI scaffolds have been validated in combination with antibiotics in vitro. Several NPs mostly flavonoids exhibit EPI activity against resistant Mycobacteria strains (Table 2) in a variety of efflux assays but there is no substantial evidence either for synergistic activity with antibiotics or specificity in respect with classes of efflux systems or inhibition patterns.

\section{Table 1. Representative NPs with EPI-activity Against Gram-Positive Bacteria}

\begin{tabular}{|c|c|c|c|c|}
\hline S. aureus EPIs & Synergist & Isolated From & EPI [C] & References \\
\hline \multicolumn{5}{|c|}{ 2-Arylbenzofuran } \\
\hline spinosan A & Berberine & Dalea spinosa & $48 \mu \mathrm{M}$ & [189] \\
\hline \multicolumn{5}{|c|}{ N-Caffeoylphenalkylamides } \\
\hline N-trans-feruloyl 4'-O-methyldopamine & Norfloxacin & Mirabilis jalapa & $100 \mathrm{mg} / \mathrm{L}$ & [190] \\
\hline \multicolumn{5}{|c|}{ Chalcones } \\
\hline chalcone & Berberine & D. versicolor & $10 \mathrm{mg} / \mathrm{L}$ & [191] \\
\hline $\begin{array}{l}\text { 7-\{[(E)-5-(3,3-dimethyl-2-oxiranyl)-3-methyl-2- } \\
\text { pentenyl }] \text { oxy }\}-2 \mathrm{H}-2 \text {-chromenone }\end{array}$ & - & - & $30 \mathrm{mg} / \mathrm{L}$ & [192] \\
\hline Galbanic acid & Ciprofloxacin & Ferula szowitsiana & $300 \mathrm{mg} / \mathrm{L}$ & [193] \\
\hline- & Ethidium Bromide & - & $0.5 \mathrm{mg} / \mathrm{L}$ & - \\
\hline \multicolumn{5}{|c|}{ Flavones } \\
\hline baicalein 5, 6, 7-trihydroxyflavone & Tetracycline & Thymus vulgaris $L$ & $\mathrm{n} / \mathrm{a}$ & [194] \\
\hline
\end{tabular}


Table 1. Contd.....

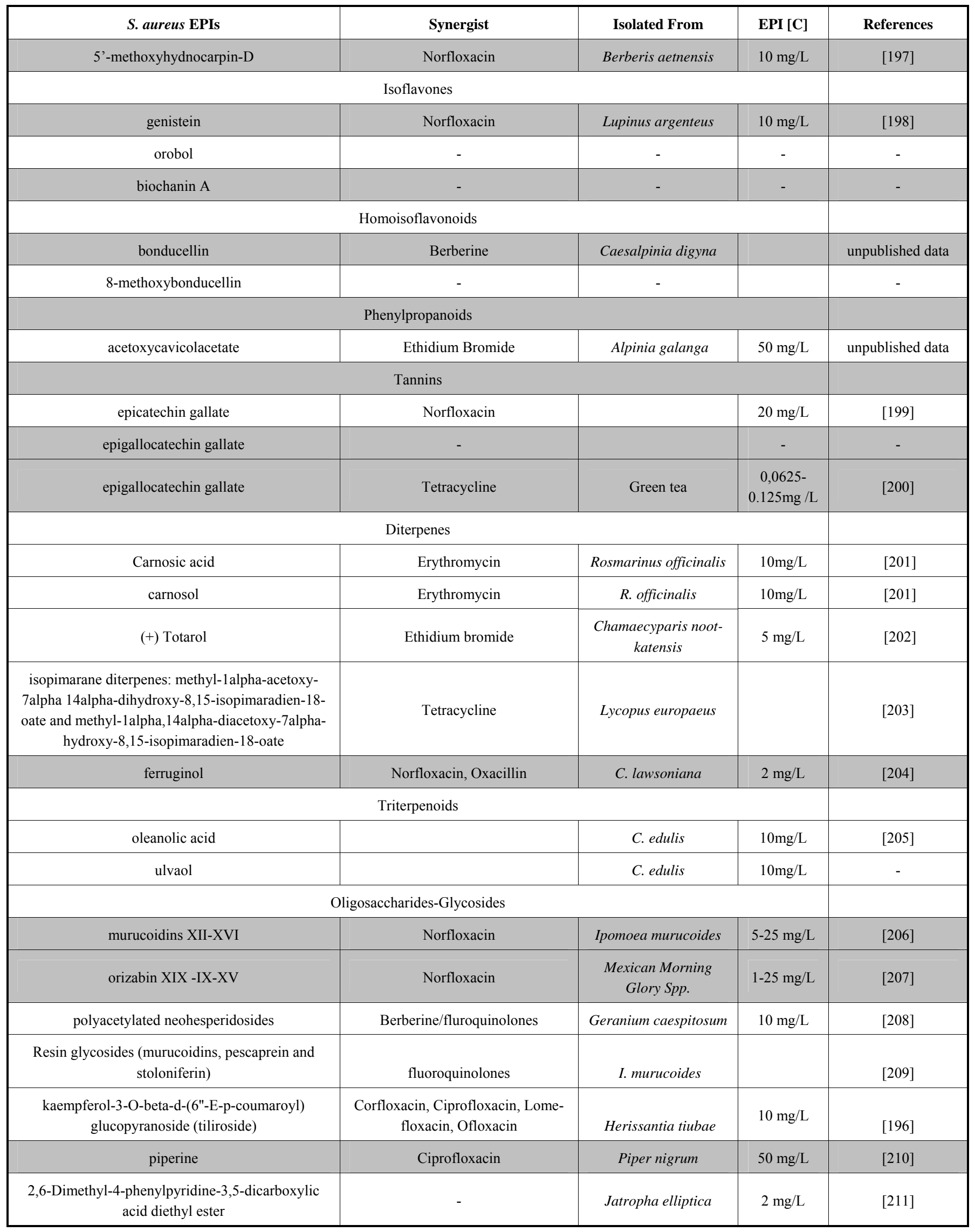


Table 1. Contd.....

\begin{tabular}{|c|c|c|c|c|}
\hline S. aureus EPIs & Synergist & Isolated From & EPI [C] & References \\
\hline reserpine & Tetracycline, Norfloxacin & Rauwolfia vomitoria & & [19] \\
\hline ergotamine & Norfloxacin & Claviceps purpurea & & [19] \\
\hline pheophorbide a & Ciprofloxacin & Berberis aetnensis & $0.5 \mathrm{mg} / \mathrm{L}$ & [213] \\
\hline indoles, indirubicin & Ciprofloxacin & $\begin{array}{l}\text { Wrightia tinctoria } R . \\
\qquad r .\end{array}$ & $\begin{array}{c}12.5-25 \\
\mathrm{mg} / \mathrm{L}\end{array}$ & [215] \\
\hline \multicolumn{4}{|c|}{ Pyridines } & \\
\hline $\begin{array}{l}\text { 2,6-dimethyl-4-phenyl-pyridine-3,5-dicarboxylic } \\
\text { acid diethyl ester }\end{array}$ & fluoroquinolones & \multicolumn{2}{|c|}{ Jatropha elliptica } & {$[192,211]$} \\
\hline
\end{tabular}

Table 2. Representative NPs with Mycobacterial EPI-Activity

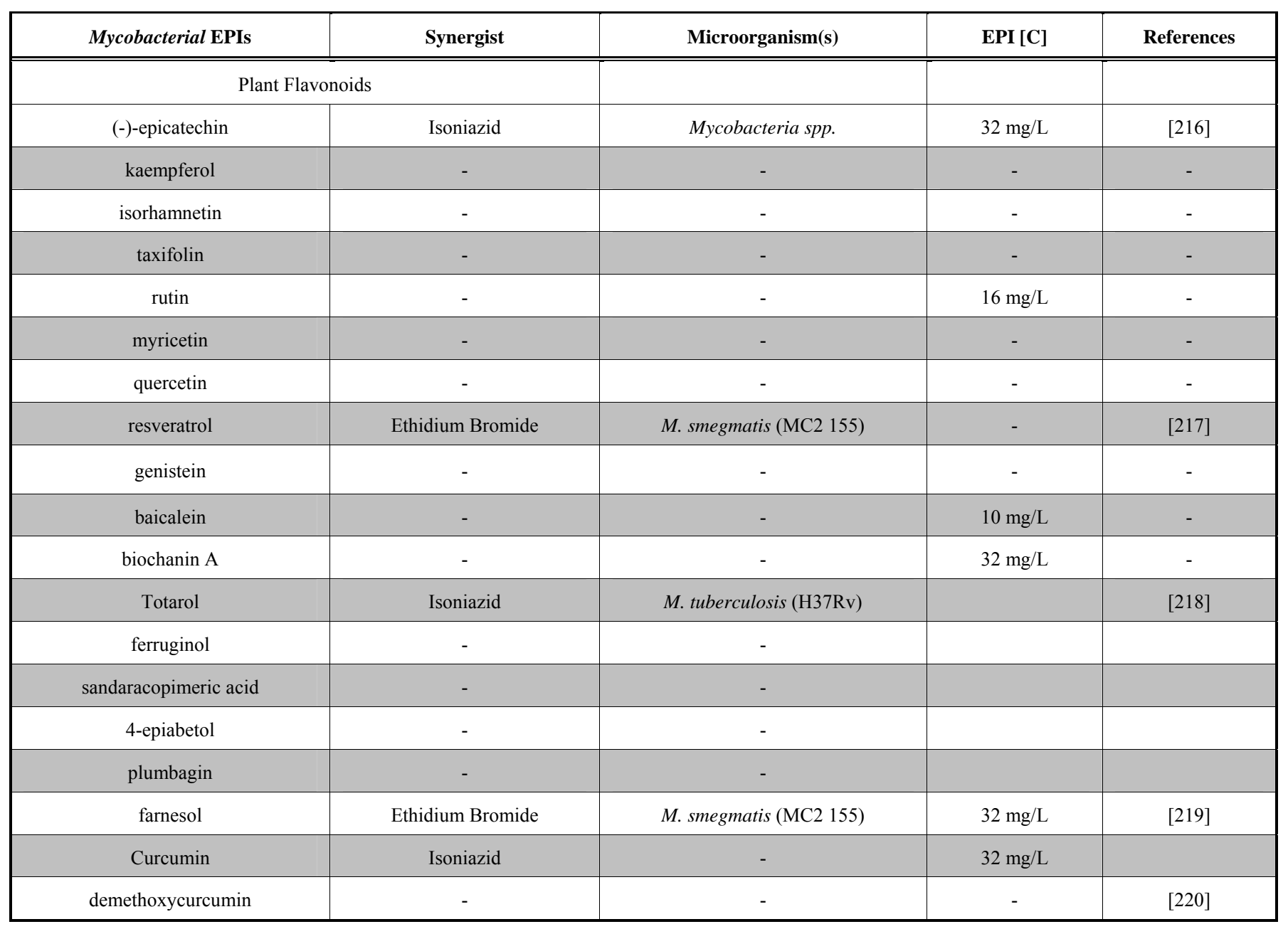

The pan resistance ability of Gram-negatives triggered a number of sophisticated EPI discovery strategies. The number of chemotypes is substantially smaller in comparison with Gram-positives but the number of available studies employing the core of EPIs is comprehensive. Phenyl-argininebeta-naphthylamide $(\mathrm{Pa} \beta \mathrm{N})$ was the first EPI identified in $P$. aeruginosa by assaying an array of synthetic compounds and natural products using strains over-expressing each of the three MES (MexAB-OprM, MexCD-OprJ, MexEF-OprN) in the presence of levofloxacin. It has been a valuable tool for drug discovery [144]. This approach has explored: i) the development of preclinical candidates including strategies for lead optimization; ii) activity in vivo through alternative scaffolds; iii) optimization of potency in the pyri- 
dopyrimidine series through the application of a pharmacophore model; and iv) extensive structural activity relationships in toxicity, stability and solubility. Mechanistically, it has been proposed that PA $\beta N$ itself is an RND competitive substrate. It seems that $\mathrm{PA} \beta \mathrm{N}$ may recognize and bind to the substrate pocket specific to the potentiated antibiotics. Alternatively, due to a proximal binding site, the EPI may also generate steric hindrance, impairing the antibiotic binding at its affinity site. PA $\beta \mathrm{N}$ has been validated against the AcrABTolC in a variety of Gram-negative pathogens (K. pneumoniae, E. coli, S. typhimurium E. aerogenes) and multiple homologous systems (A. baumannii, Campylobacter sp.). Naphthylpiperazines, notably 1-naphthylmethyl-piperazine (NMP) are among the most potent unsubstituted arylpiperazines, with a dose-dependent ability to increase the intracellular concentration of several antibiotics [145]. NMP seems to be effective in A. baumannii and several Enterobacteriaceae $[145,146]$. The list also includes trimethoprim and epinephrine, indole derivatives and quinolone derivatives [147]. Recently, artesunate was found to enhance the antibacterial effect of beta-lactam antibiotics against $E$. coli by increasing antibiotic accumulation via inhibition of AcrABTolC [148]. A number of NPs have been implicated in Gram-negative efflux inhibition (Table 3). Again the list is chemotypes is limited and the mechanistic implications unexploited. As a general rule, it is challenging to identify NPs with Gram-negative EPI properties with the available functional or phenotypic efflux assays [149, 150]. In a recent study, total alkaloids of Sophora alopecuroides-induced down-regulation of AcrAB-TolC and reverse susceptibility to ciprofloxacin in MDR E. coli isolates [151].

There is a core of natural products that can enhance the potency of antifungals: 1. Tacrolimus isolated from the fermentation broth of Streptomyces tsukubaensis and when added in sub-inhibitory concentrations $\left(10^{-5}\right.$ to $\left.10^{-3} \mathrm{mM}\right)$ can reduce 16-fold the MIC of itricanazole in the CDR1expressing resistant strain C. albicans and 8-fold in a CaMDR-expressing resistant strain [152]. 2. The cyclodepsipeptides unnaramicin $\mathrm{A}$ and unnaramicin $\mathrm{C}$ isolated from the extracts of marine bacterium Photobacterium sp reduce the MIC of fluconazole by 64 -fold $(320 \mathrm{mg} / \mathrm{L}$ to $5 \mathrm{mg} / \mathrm{L})$ against azole-resistant $C$. albicans at relatively low $(1.25 \mu \mathrm{M}-$ $5 \mu \mathrm{M})$ concentration $[153,154]$. 3. Geodisterol-3-O-sulfite and 29-demethylgeodisterol-3-O-sulfite isolated from marine sponge Topsentia sp. enhanced the activity of fluconazole against overexpressed MDR1 in clinical isolate of C. albicans [155]. 4. Enniatin B reduced the $\mathrm{IC}_{50}$ of cyclohexamide 8 -fold ( 0.13 to $0.016 \mu \mathrm{g} / \mathrm{mL}$ ) against a $\mathrm{Pdr} 5 \mathrm{p}$-overexpressing strain of Saccharomyces cerevisiae at $6.0 \mu \mathrm{M}$ [156]. 5. Milbemycins $\alpha_{9}$ found to enhance the activity of fluconazole and the triazole SCH-56592 against clinical isolates of C. albicans [157].

\section{EPI Combined with PDT}

The concept of synergistic action of antimicrobials with EPIs has been exploited in PDT to potentiate the phototoxic action of phenothiazinium PSs [158]. The PDT effect of MB or TBO was substantially enhanced by small molecule EPIs in $S$. aureus that affect NorA as assessed by both reduction of viable cells and fluorescent dye accumulation. The potentiation is less pronounced against $P$. aeruginosa with Mex $\mathrm{AB}[158]$.

Table 3. Representative NPs with EPI-Activity against Gram-Negative Bacteria (EPI [C] is Ranging between 10-50mg/L)

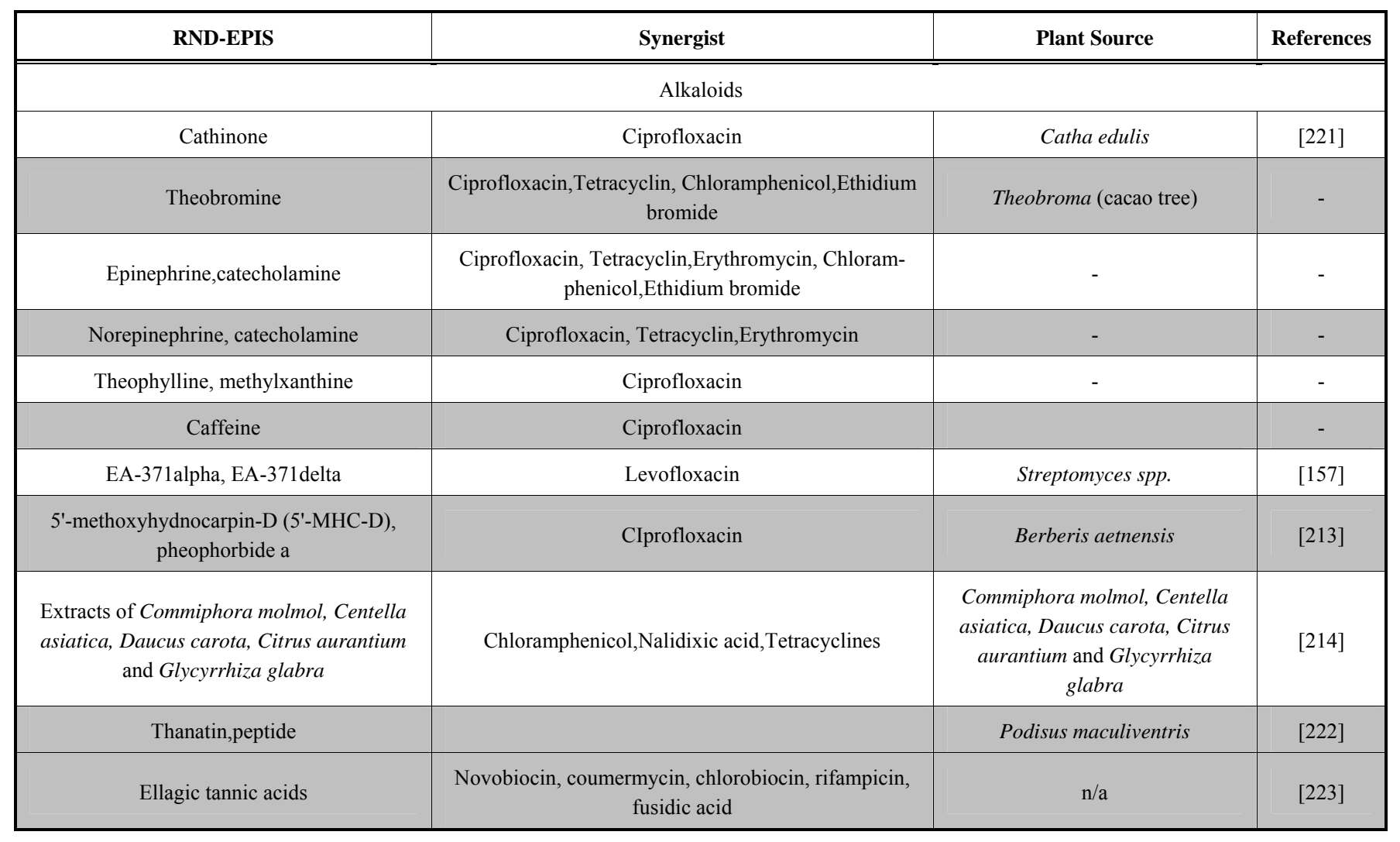


Prates et al. tested this hypothesis by comparing MBPDI for two pairs of isogenic C. albicans strains i) YEM 12 and YEM 13 mutant overexpressing MDR1 MFS; and ii) YEM 14 and YEM 15 mutant overexpressing CDR1/CDR2. Since efflux systems affect APDI of MB in C. albicans, a logical strategy was to explore whether EPIs could potentiate antimicrobial PDI (APDI) with MB. They used two welldocumented EPIs, one for each corresponding efflux system, $\mathrm{INF}_{271}$ (targeting MFS) and verapamil (+) (targeting ABCs both in yeast and mammalian systems) and the reference $C$. albicans strain DAY185. Pre-exposure to $\mathrm{INF}_{271}$ followed by MB mediated PDI, resulted in a paradoxical protection rather than enhancement of phototoxicity. On the other hand, pre exposure of C. albicans cells to verapamil $(+)$ and subsequent MB-mediated APDI led to an increase of phototoxicity when compared with the PDI efficacy of MB in the absence of EPIs. In addition, pre exposure of the CDR1/CDR2 overexpressing mutant YEM 15 in verapamil $(+)$ and subsequent APDI revealed $2 \operatorname{logs}_{10}$ of cell reduction in the presence of the EPI, in comparison with virtually no effect in the absence of the ABC pump blocker. The authors demonstrated that $\mathrm{ABC}$ pumps are directly implicated in $\mathrm{MB}$ efflux from the cell cytoplasm.

\section{Animal Models of Infection, and the Challenge of Clini- cal EPI Implementation}

A major obstacle to the path of microbial EPI implementation may arise from the fact that efflux systems manipulation could cause unexpected toxicities due to the multitude of physiological roles MES may play in human cells. In this context, efforts directed at specifically inhibiting efflux pumps operating only in prokaryotes may offer a greater chance of therapeutic success. Interestingly, it has been shown that target bacteria respond to clinical challenge with EPIs by developing resistance mutations that decrease the efficacy of the EPI $[159,160]$. In the same context, it was demonstrated that reserpine can select multidrug resistant Streptococcus pneumoniae strains [161].

The threat of cross-resistance to different antibiotics elevates the complexity of EPI discovery ventures. Addressing this requires that efflux substrates and inhibitors be clearly differentiated, this may be also of interest for the PS for use in antimicrobial PDT. The latter case will demand rational approaches that simultaneously address both the photochemical mechanistic aspects of PDT and efflux phenotypic variations. A reported strategy of "dual antimicrobial action" targeting NorA in Gram-positive bacteria provides a path forward towards addressing these issues. A hybrid compound (SS14) was created by fusing the plant antimicrobial berberine to the synthetic NorA EPI INF55. SS14 was established as an effective antimicrobial against $S$. aureus, (100fold more effective than the berberine parent molecule) including mutant strains that over express NorA [162]. MIC's for SS14 against $S$. aureus are interestingly 2-16 times lower than berberine in combination with the EPI INF55 when present together. The hybrid rapidly accumulated in bacterial cells and showed higher efficacy than vancomycin in a Caenorhabditis elegans model of enterococcal infection [162]. Analogs of SS14 exhibited similar antimicrobial activities $[163,164]$ suggesting that significant structural changes can be made to these hybrids without adversely affecting their ability to block MES or their antibacterial activity. Further compelling the cytotoxicity associated with INF55 was found absent in the hybrid SS14. Such hybrids are predicted to have an advantage over separate compound administration in terms of synchronous or near synchronous delivery of both agents to the appropriate bacterial target sites. Interestingly -conjugation of the indole derivatives to ciprofloxacin rendered the hybrid orders of magnitude less effective than ciprofloxacin alone (Anthony Ball unpublished data). Perhaps the lesson is antibiotics are not ideal candidates for hybrid strategies; but rather antimicrobials; or agents with a non-specific mechanism of action are perhaps the better suited for conjugate approaches. It is noteworthy that plants evolved a complex milieu of toxins and synergists which are synthesized in defense against microbial attack and that such a technique differs largely from that strategy employed by antibiotic producing microbes.

Among the potential roles, it has been demonstrated that efflux pumps are important for processes of detoxification of intracellular metabolites, bacterial virulence in both animal and plant hosts, cell homeostasis and intercellular signal trafficking [165]. Researchers have engaged in new antimicrobial development tractable whole-animal screens that utilize the well-studied nematode C. elegans, the great wax moth Galleria mellonella, the fruit fly Drosophilla melanogaster and the zebra fish. Those have been employed as model hosts to identify and develop new classes of antimicrobial agents with antivirulence or immunomodulatory efficacy and evaluate toxicity or efficacy. The amenability of these nonvertebrate hosts to large screens has made them invaluable in drug discovery against either bacterial or fungal pathogens [166-168]. The design of host-pathogen studies exploring the ability of efflux to interfere with virulence determinants sounds promising and highly informative but often requires more sophisticated tools and approaches as the results varies. For example, C. elegans was used to assess the fitness of in vitro selected $P$. aeruginosa MexABOprM (nalB) and MexCDOprJ (nfxB) multidrug resistant mutants [169] and to confirm that overproduction of MexEF-OprN does not impair $P$. aeruginosa fitness in competition tests, but produces specific changes in bacterial regulatory networks [170]. B. pseudomallei is able to cause 'disease-like' symptoms and kill the nematode but all the indication are that the killing mechanism is not related with efflux systems that pump out either aminoglycosides or macrolides [171]. In a similar fashion C. elegans and an array of antimicrobials were valuable tools in correlating membrane efflux and influx with both multidrug resistance and virulence of $K$. pneumoniae [172].

The nematode model was employed to validate the antimicrobial potential of the dual action antimicrobial hybrids in a variety of pathogens $[162,164]$ but also to demonstrate that the quorum sensing inhibitor C-30 (brominated furanone) can trigger rapidly efflux mutations in $P$. aeruginosa [173]. In a recent example employing C. elegans it was demonstrated RamA, a member of the AraC/XylS family, influences both virulence and efflux in S. enterica serovar Typhimurium [174]. In a unique example the nematode model was pivotal to dissect the mechanism that Pdr1p family members in S. cerevisiae and C. glabrata use and directly 
bind to structurally diverse drugs and xenobiotics, resulting in stimulated expression of drug efflux pumps [175].

The reports that correlate the rest of the model hosts with efflux are not extensive. G. melonella was employed to validate the efficacy of azithromycin against intracellular infections of Francisella [176]. AcrAB-TolC mutants were used only in vitro and were not employed to infect the caterpillars. $D$. melanogaster was a valuable tool to display the virulence characteristics and resistance patterns of the Liverpool epidemic strain (LES) of $P$. aeruginosa, a transmissible aggressive pathogen of cystic fibrosis (CF) patients [177]. Мyсоbacterium marinum-infected zebrafish larvae for in vivo characterization of antitubercular drug activity and tolerance. It was demonstrated that efflux systems required for intracellular growth mediate this macrophage-induced tolerance. This tolerant population also developed when M. tuberculosis infects cultured macrophages, suggesting that it contributed to the burden of drug tolerance in human tuberculosis. Verapamil was shown to reduce that tolerance [178].

The results for EPI efficacy in murine models are limited and inconclusive. The combination of piperine with mupirocin in a mice dermal infection model showed better in vivo efficacy when compared with the commercially available formulation of $2 \%$ mupirocin [179]. Using a mouse model of lethal infection, it was demonstrated that concomitant administration of the lactoferricin-derived peptide P2-15 and erythromycin against $P$. aeruginosa afforded long-lasting protection to one-third of the animals [180]. A d-octapeptide EPI acts synergistically with azoles in a murine oral candidiasis infection model [181]. In a latest in vivo study, PDT employing EPIs was able to reduce bacterial load in $P$. aeruginosa burn wounds, to delay bacteremia and to keep the bacterial levels in blood 2-3 $\log _{10}$ lower compared to an untreated group [182].

A number of fitness and in vivo modeling studies have been conducted using different mice models. In MRSA MW2 (USA400 lineage) for example, NorB facilitated bacterial survival upon overexpression in a staphylococcal abscess and may contribute to the relative resistance of abscesses to antimicrobial therapy, thus linking bacterial fitness and resistance in vivo [183]. An intraperitoneal mouse model of systemic infection was used to evaluate the role of AcrAB-TolC on antimicrobial resistance in vivo employing clinical isolates of Enterobacter cloacae overexpressing or lacking parts of the RND efflux system. This approach, revealed reduced virulence in both E. cloacae clinical strains when either the acrA or tolC genes were inactivated [184]. Similar studies with emphasis in the AcrAB-TolC system have been conducted in a variety of $F$. tularensis strains including the live vaccine strain (LVS) $[185,186]$ and SCHU S4 [187].

\section{CONCLUSION}

The lengthy description of this array of endeavors leads in four main conclusions: a. Tools and technological platforms for EPI discovery are available and rapidly advancing with emphasis on flow cytometry and imaging. b. A core of NP chemotypes has been validated as EPIs in many pathogenic systems but the real challenge of discovery remains Gram-negatives. c. PDT and other alternative antimicrobial strategies may provide a niche for EPI implementation. This statement requires further elaboration: Efflux systems have been evolutionary co-ordinate to pump out a broad range of non-specific compounds including potential toxins which do not attack a single target. Indeed many efflux substrates are generally active against microbial membranes and DNA neither of which is essentially mutable. Antimicrobial PS, like amphipathic cations represent old and familiar enemies to the microbial efflux systems and APDI potentiation with EPIs NPs seems like a broader scheme with multi fold applications. NP EPIs have shown remarkable efficacy in potentiating largely ineffective antimicrobials such as berberine. PDT is able to exhibit substantially higher cidal efficacy than the traditional plant antimicrobials. This concept may apply by incorporating PS and PDT-based applications to the current hybrid models which employ traditional antibiotics (evolution has already refined to reasonably evade efflux systems with their neutral moieties) or plant based antimicrobials (they are only marginally effective and only within the presence of EPIs; or multiple EPIs within the plant's natural environment). d. An apparent methodological gap between in vitro and preclinical studies remains and hostpathogen interactive expeditions incorporating EPIs are not providing conclusive results. Although the progress in highlighting the role that MES play in microbial ecology survival and virulence seems to be slow but satisfactory, the hurdles and challenges associated with antimicrobial drug EPI-based design remain overwhelming.

\section{CONFLICTS OF INTEREST}

The authors confirm that this article content has no conflicts of interest.

\section{ACKNOWLEDGEMENTS}

George $\mathrm{P}$ Tegos is supported by the NIH (grant 5U54MH084690-02). Research conducted in the Hamblin Laboratory was supported by NIH (R01 AI050875 to MRH) and US Air Force MFEL Program (FA9550-04-1-0079).

\section{ABBREVIATIONS}

$\begin{array}{ll}\text { ABC } & =\text { ATP Binding Cassette } \\ \text { APDI } & =\text { Antimicrobial Photodynamic Inactivation } \\ \text { CDR1 } & =\text { Candida Drug Resistance-1 } \\ \text { CFU } & =\text { Colony forming unit } \\ \text { EPI } & =\text { Efflux Pump Inhibitor } \\ \text { FDG } & =\text { Fluorescein-di- } \beta \text {-D-galactopyranoside } \\ \text { FICI } & =\text { Fractional Inhibitory Concentration indices } \\ \text { FLAP } & =\text { Fingerprints for Ligands and Proteins } \\ \text { HTS } & =\text { High Throughput Screening } \\ \text { LES } & =\text { Liverpool epidemic strain } \\ \text { MB } & =\text { Methylene Blue } \\ \text { MDR } & =\text { Multidrug Resistance } \\ \text { MDR1 } & =\text { Multidrug Resistance-1 } \\ \text { MIC } & =\text { Minimal Inhibitory Concentration }\end{array}$




$\begin{array}{ll}\text { MF } & =\text { Modulation Factor } \\ \text { MFS } & =\text { Major Facilitator Superfamily } \\ \mathrm{NP} & =\text { Phenyl-arginine-beta-naphthylamide } \\ \text { PaßN } & =\text { Photodynamic Inactivation } \\ \text { PDI } & =\text { Pleiotropic Drug Resistance } \\ \text { PDR } & =\text { polyethyleneimine-chlorin(e6), } \\ \text { PDT } & =\text { P-glycoprotein } \\ \text { PEI-ce6 } & =\text { Photosensitizer } \\ \text { P-gp } & =\text { Quantitative Structure-Activity Relation- } \\ \text { PS } & \text { ships } \\ \text { QSAR } & =\text { Rose Bengal } \\ \text { RB } & =\text { Resistant Nodulation (cell) Division } \\ \text { RND } & =\text { Rhodamine 6-G } \\ \text { ROS } & =\text { Toluidine Blue } \\ \text { R6G } & =\end{array}$

\section{REFERENCES}

[1] Binder S, Levitt AM, Sacks JJ, Hughes JM. Emerging infectious diseases: public health issues for the 21st century. Science 1999; 284:1311-3.

[2] Alekshun M, Levy SB. Molecular mechanisms of antibacterial multidrug resistance. Cell 2007; 128: 1037-50.

[3] Piddock L. Clinically relevant chromosomally encoded multidrug resistance efflux pumps in bacteria. Clin Microbiol Rev 2006;19: 382-402.

[4] Cannon R, Lamping E, Holmes AR, et al. Efflux-mediated antifungal drug resistance. Clin Microbiol Rev 2009; 2: 291-321.

[5] Paulsen IT, Chen J, Nelson KE, Saier MHJ. Comparative genomics of microbial drug efflux systems. In: Lewis K, Ed. Microbial multidrug efflux. Norfolk: Horizon Press 2002.

[6] Tegos GP, Haynes M, Strouse JJ, et al. Microbial Efflux Inhibition; tactics \& strategies. Curr Pharm Des 2011; 17: 1291-302.

[7] Ren Q, Paulsen, IT. Comparative analyses of fundamental differences in membrane transport capabilities in prokaryotes and eukaryotes. PLoS Comput Biol 2005; 3: e27.

[8] Fletcher JI, Haber M, Henderson MJ, Norris MD. ABC transporters in cancer: more than just drug efflux pumps. Nat Rev Cancer 2010; 10: $147-56$.

[9] Nikaido H. Multidrug efflux pumps of gram-negative bacteria. J Bacteriol 1996; 178: 5853-9.

[10] Li X, Nikaido H. Efflux-mediated drug resistance in bacteria: an update. Drugs 2009; 69:1555-623.

[11] Lee A, Mao W, Warren MS, et al. Interplay between efflux pumps may provide either additive or multiplicative effects on drug resistance. J Bacteriol 2000; 182: 3142-50.

[12] Tal N, Schuldiner S. A coordinated network of transporters with overlapping specificities provides a robust survival strategy. Proc Natl Acad Sci USA 2009; 106: 9051-6.

[13] Takatsuka Y, Chen C, Nikaido H. Mechanism of recognition of compounds of diverse structures by the multidrug efflux pump AcrB of Escherichia coli. Proc Natl Acad Sci USA 2010; 107: 6559-65.

[14] Symmons M, Bokma E, Koronakis E, Hughes C, Koronakis V. The assembled structure of a complete tripartite bacterial multidrug efflux pump. Proc Natl Acad Sci USA 2009; 106: 7173-8.

[15] Yao X, Kenzaki H, Murakami S, Takada S. Drug export and allosteric coupling in a multidrug transporter revealed by molecular simulations. Nat Commun 2010; $1: 117$.

[16] Amaral L, Fanning S, Pagès JM. Efflux pumps of gram-negative bacteria: genetic responses to stress and the modulation of their activity by $\mathrm{pH}$, inhibitors, and phenothiazines. Adv Enzymol Relat Areas Mol Biol 2011; 77: 61-108.

[17] $\mathrm{Su} \mathrm{C}, \mathrm{Li} \mathrm{M}, \mathrm{Gu}$ R, et al. Conformation of the AcrB multidrug efflux pump in mutants of the putative proton relay pathway. J Bacteriol 2006; 188: 7290-6.

[18] Amaral L, Cerca P, Spengler G, et al. Ethidium bromide efflux by Salmonella: modulation by metabolic energy, $\mathrm{pH}$, ions andphenothiazines. Int J Antimicrob Agents 2011; 38: 140-5.

[19] Gibbons S. Phytochemicals for bacterial resistance--strengths, weaknesses and opportunities. Planta Med 2008; 74: 594-602.

[20] McAleese F, Petersen P, Ruzin A, et al. A novel MATE family efflux pump contributes to the reduced susceptibility of laboratoryderived Staphylococcus aureus mutants to tigecycline. Antimicrob Agents Chemother 2005; 49:1865-71.

[21] Narui K, Noguchi N, Wakasugi K, Sasatsu M. Cloning and characterization of a novel chromosomal drug efflux gene in Staphylococcus aureus. Biol Pharm Bull 2002; 25: 1533-6.

[22] Brown M, Skurray RA. Staphylococcal multidrug efflux protein QacA. J Mol Microbiol Biotechnol 2001; 3: 163-70.

[23] Xu Z, O'Rourke BA, Skurray RA, Brown MH. Role of transmembrane segment 10 in efflux mediated by the staphylococcal multidrug transport protein QacA. J Biol Chem 2006; 281: 792-9.

[24] Jin J, Guffanti AA, Bechhofer DH, Krulwich TA. Tet(L) and tet(K) tetracycline-divalent metal/ $\mathrm{H}^{+}$antiporters: characterization of multiple catalytic modes and a mutagenesis approach to differences in their efflux substrate and coupling ion preferences. J Bacteriol 2002; 184: 4722-32.

[25] Jonas BM, Murray BE, Weinstock GM. Characterization of emeA, a NorA homolog and multidrug resistance efflux pump, in Enterococcus faecalis. Antimicrob Agents Chemother 2001; 45: 3574-9.

[26] Lewis K. in search of natural substrates and inhibitors of MDR pumps. J Mol Microbiol Biotechnol 2001; 3: 247-54.

[27] Tegos G, Stermitz FR, Lomovskaya O, Lewis K. Multidrug pump inhibitors uncover remarkable activity of plant antimicrobials. Antimicrob Agents Chemother 2002; 46: 3133-41.

[28] Nordmann P, Naas T, Fortineau N, Poirel L. Superbugs in the coming new decade; multidrug resistance and prospects for treatment of Staphylococcus aureus, Enterococcus spp. and Pseudomonas aeruginosa in 2010. Curr Opin Microbiol 2007;10: 436-40.

[29] Dijkshoorn L, Nemec A, Seifert H. An increasing threat in hospitals: multidrug-resistant Acinetobacter baumannii. Nat Rev Microbiol 2007; 5: 939-51.

[30] Poole K. Pseudomonas aeruginosa: resistance to the max. Front Microbiol 2011; 2: 65.

[31] Mima T, Kohira N, Li Y, et al. Gene cloning and characteristics of the RND-type multidrug efflux pump MuxABC-OpmB possessing two RND components in Pseudomonas aeruginosa. Microbiology 2009; 155: 3509-17.

[32] Mima T, Joshi S, Gomez-Escalada M, Schweizer HP. Identification and characterization of TriABC-OpmH, a triclosan efflux pump of Pseudomonas aeruginosa requiring two membrane fusion proteins. J Bacteriol 2007; 189: 7600-9.

[33] Schell M, Zhao P, Wells L. Outer membrane proteome of Burkholderia pseudomallei and Burkholderia mallei from diverse growth conditions. J Proteome Res 2011; 10: 2417-24.

[34] Bazzini S, Udine C, Sass A, et al. Deciphering the role of RND efflux transporters in Burkholderia cenocepacia. PLoS ONE 2011; 6: e18902.

[35] Ueda O, Wexler HM, Hirai K, Shibata Y, Yoshimura F, Fujimura S. Sixteen homologs of the mex-type multidrug resistance efflux pump in Bacteroides fragilis. Antimicrob Agents Chemother 2005; 49: 2807-15.

[36] Damier-Piolle L, Magnet S, Brémont S, Lambert T, Courvalin P. AdeIJK, a resistance-nodulation-cell division pump effluxing multiple antibiotics in Acinetobacter baumannii. Antimicrob Agents Chemother 2008; 52: 557-62.

[37] Lin L, Ling BD, Li XZ. Distribution of the multidrug efflux pump genes, ade $\mathrm{ABC}$, adeDE and adeIJK, and class 1 integron genes in multiple-antimicrobial-resistant clinical isolates of Acinetobacter baumannii-Acinetobacter calcoaceticus complex. Int J Antimicrob Agents 2009; 33: 27-32.

[38] Cortez-Cordova J, Kumar A. Activity of the efflux pump inhibitor phenylalanine-arginine $\beta$-naphthylamide against the AdeFGH 
pump of Acinetobacter baumannii. Int J Antimicrob Agents 2011; 37: 420-4.

[39] Matsuo T, Chen J, Minato Y, et al. SmdAB, a heterodimeric ABCType multidrug efflux pump, in Serratia marcescens. J Bacteriol 2008; 190: 648-54.

[40] Tikhonova E, Devroy VK, Lau SY, Zgurskaya HI. Reconstitution of the Escherichia coli macrolide transporter: the periplasmic membrane fusion protein MacA stimulates the ATPase activity of MacB. Mol Microbiol 2007; 63: 895-910.

[41] Rouquette-Loughlin C, Balthazar JT, Shafer WM. Characterization of the MacA-MacB efflux system in Neisseria gonorrhoeae. J Antimicrob Chemother 2005; 56: 856-60.

[42] Santiviago C, Fuentes JA, Bueno SM, et al. The Salmonella enterica sv. Typhimurium smvA, yddG and ompD (porin) genes are required for the efficient efflux of methyl viologen. Mol Microbiol 2002; 46: 687-98.

[43] Nishino K, Yamaguchi A. Analysis of a complete library of putative drug transporter genes in Escherichia coli. J Bacteriol 2001; 183: 5803-12.

[44] Rodríguez-Martínez J, Cano ME, Velasco C, Martínez-Martínez L, Pascual A. Plasmid-mediated quinolone resistance: an update. J Infect Chemother 2011; 17: 149-82.

[45] Coyne S, Courvalin P, Périchon B. Efflux-mediated antibiotic resistance in Acinetobacter spp. Antimicrob Agents Chemother 2011; 55: 947-53.

[46] Rajamohan G, Srinivasan VB, Gebreyes WA. Molecular and functional characterization of a novel efflux pump, AmvA, mediating antimicrobial and disinfectant resistance in Acinetobacter baumannii. J Antimicrob Chemother 2010; 65: 1919-25.

[47] He G, Zhang C, Crow RR, et al. SugE, a new member of the SMR family of transporters, contributes to antimicrobial resistance in Enterobacter cloacae. Antimicrob Agents Chemother 2011; 55: 3954-7.

[48] Da Silva P, Von Groll A, Martin A, Palomino JC. Efflux as a mechanism for drug resistance in Mycobacterium tuberculosis. FEMS Immunol Med Microbiol 2011; 63: 1-9.

[49] Aínsa J, Blokpoel MC, Otal I, Young DB, De Smet KA, Martín C. Molecular cloning and characterization of Tap, a putative multidrug efflux pump present in Mycobacterium fortuitum and Mycobacterium tuberculosis. J Bacteriol 1998; 180: 5836-43.

[50] De Rossi E, Arrigo P, Bellinzoni M, et al. The multidrug transporters belonging to major facilitator superfamily in Mycobacterium tuberculosis. Mol Med 2002; 8: 714-24.

[51] Balganesh M, Dinesh N, Sharma S, Kuruppath S, Nair AV, Sharma U. Efflux Pumps of Mycobacterium tuberculosis play a significant role in anti-tuberculosis activity of potential drug candidates. Antimicrob Agents Chemother 2012; 56: 2643-51.

[52] Choudhuri B, Bhakta S, Barik R, Basu J, Kundu M, Chakrabarti P. Overexpression and functional characterization of an ABC (ATPbinding cassette) transporter encoded by the genes drrA and drrB of Mycobacterium tuberculosis. Biochem J 2002; 367: 279-85.

[53] Danilchanka O, Mailaender C, Niederweis M. Identification of a novel multidrug efflux pump of Mycobacterium tuberculosis. Antimicrob Agents Chemother 2008; 52: 2503-11.

[54] Hao P, Shi-Liang Z, Ju L, et al. The role of ABC efflux pump, Rv1456c-Rv1457c-Rv1458c, from Mycobacterium tuberculosis clinical isolates in China. Folia Microbiol (Praha) 2011; 56: 54953.

[55] Buroni S, Manina G, Guglierame P, Pasca MR, Riccardi G, De Rossi E. LfrR is a repressor that regulates expression of the efflux pump LfrA in Mycobacterium smegmatis. Antimicrob Agents Chemother 2006; 50: 4044-52.

[56] Li X, Zhang L, Nikaido H. Efflux pump-mediated intrinsic drug resistance in Mycobacterium smegmatis. Antimicrob Agents Chemother 2004; 48: 2415-23.

[57] De Rossi E, Branzoni M, Cantoni R, Milano A, Riccardi G, Ciferri O. mmr, a Mycobacterium tuberculosis gene conferring resistance to small cationic dyes and inhibitors. J Bacteriol 1998; 180: 606871.

[58] Lamping E, Baret PV, Holmes AR, Monk BC, Goffeau A, Cannon RD. Fungal PDR transporters: Phylogeny, topology, motifs and function. Fungal Genet Biol 2010; 47: 127-42.

[59] Paumi CM, Chuck M, Snider J, Stagljar I, Michaelis S. ABC transporters in Saccharomyces cerevisiae and their interactors: new technology advances the biology of the ABCC (MRP) subfamily. Microbiol Mol Biol Rev 2009; 73: 577-93.

[60] Holmes AR, Lin YH, Niimi K, et al. ABC transporter Cdr1p contributes more than $\mathrm{Cdr} 2 \mathrm{p}$ does to fluconazole efflux in fluconazole-resistant Candida albicans clinical isolates. Antimicrob Agents Chemother 2008; 52(11): 3851-62.

[61] Cannon RD, Lamping E, Holmes AR, et al. Efflux-mediated antifungal drug resistance. Clin Microbiol Rev 2009; 22: 291-321.

[62] Holmes AR, Tsao S, Ong SW, et al. Heterozygosity and functional allelic variation in the Candida albicans efflux pump genes CDR1 and CDR2. Mol Microbiol 2006; 62: 170-86.

[63] Hamblin M, Hasan T. Photodynamic therapy: a new antimicrobial approach to infectious disease? Photochem Photobiol Sci 2004; 3(5): 436-50.

[64] Mitton D, Ackroyd R. A brief overview of photodynamic therapy in Europe. Photodiagnosis Photodyn Ther 2008; 5: 103-11.

[65] St. Denis T, Dai T, Izikson A, et al. All you need is light antimicrobial photoinactivation as an evolving and emerging discovery strategy against infectious disease. Virulence 2011;2: 112.

[66] Wainwright M, Byrne MN, Gattrell MA. Phenothiazinium-based photobactericidal materials. J Photochem Photobiol B 2006; 84(3): 227-30.

[67] Huang L, Huang YY, Mroz P, et al. Stable synthetic cationic bacteriochlorins as selective antimicrobial photosensitizers. Antimicrob Agents Chemother 2010; 54: 3834-41.

[68] Castano A, Demidova TN, Hamblin MR. Mechanisms in photodynamic therapy: part one-photosensitizers, photochemistry and cellular localization. Photodiagnosis Photodyn Ther 2004; 1 : 279-93.

[69] Schafer M, Schmitz C, Facius R, et al. Systematic study of parameters influencing the action of Rose Bengal with visible light on bacterial cells: comparison between the biological effect and singlet-oxygen production. Photochem Photobiol 2000; 71: 514-23.

[70] Harris F, Chatfield LK, Phoenix DA. Phenothiazinium based photosensitisers--photodynamic agents with a multiplicity of cellular targets and clinical applications. Curr Drug Targets 2005; 6: 615-27.

[71] Tegos G, Demidova TN, Arcila-Lopez D, et al. Cationic fullerenes are effective and selective antimicrobial photosensitizers. Chem Biol 2005; 12: 1127-35.

[72] Huang L, Terakawa M, Zhiyentayev T, et al. Innovative cationic fullerenes as broad-spectrum light-activated antimicrobials. Nanomedicine 2010; 6: 442-52.

[73] Fisher W, Partridge WP Jr, Dees C, Wachter EA. Simultaneous two-photon activation of type-I photodynamic therapy agents. Photochem Photobiol 1997; 66: 141-55.

[74] Plaetzer K, Krammer B, Berlanda J, Berr F, Kiesslich T. Photophysics and Photochemistry of photodynamic therapy: fundamental aspects. Lasers Med Sci 2009; 24: 259-68.

[75] Maisch T. A new strategy to destroy antibiotic resistant microorganisms: antimicrobial photodynamic treatment. Mini Rev Med Chem 2009; 9: 974-83.

[76] Paterson M, Bergendahl LT. Computational Modelling of the Steps Involved in Photodynamic Therapy. In: Sahas S, Ed. Molecular Photochemistry - Various Aspects 2012.

[77] Quartarolo A, Russo N. On the potential use of squaraine derivatives as photosensitizers in photodynamic therapy: a tddft and ricc2 survey. J Chem Theory Comput 2009; 5: 1849-57.

[78] Serrano-Perea J, Serrano-Andrés L, Merchán M. A theoretical insight into the photophysics of psoralen. J Chem Phys 2006; 124: 124502.

[79] Glusko CA, Previtali CM, Vera DMA, Chesta CA, Montejano HA An experimental and theoretical study on the photophysical properties of methylene green. Dyes Pigm 2011; 90: 28-35.

[80] Shen L. Theoretical investigation on the triplet excited state properties of the porphyrin-related photosensitizers and the implications in illustrating their photosensitization mechanisms. J Mol Struct 2008; 862: 130-2.

[81] Quartarolo A, Lanzo I, Sicilia E, Russo N. Can phthalocyanines and their substituted alpha-para-(methoxy)phenyl derivatives act as photosensitizers in photodynamic therapy? A TD-DFT study. Phys Chem Chem Phys 2009; 11: 4586-92.

[82] Zhao X, Zheng Z, Feng S, Shi Z, Chen D. A TD-DFT Study on the Photo-Physicochemical properties of chrysophanol from Rheum. Int J Mol Sci 2009; 10: 3186-93. 
[83] Badaeva E, Timofeeva TV, Masunov A, Tretiak A. Role of donoracceptor strengths and separation on the two-photon absorption response of cytotoxic dyes: A TD-DFT Study. J Phys Chem A 2005; 109: 7276-84.

[84] Sun W, Li Z, Badaeva E, et al. Tuning Photophysics and nonlinear absorption of bipyridyl Platinum(II) Bisstilbenylacetylide complexes by auxiliary substituents. J Phys Chem A 2012; 116(20): 4878-89.

[85] Arnbjerg J, Jiménez-Banzo A, Paterson MJ, et al. Two-Photon Absorption in tetraphenylporphycenes: are porphycenes better candidates than porphyrins for providing optimal optical properties for two-photon photodynamic therapy? J Am Chem Soc 2007; 129: 5188-99.

[86] Segalla A, Borsarelli CD, Braslavsky SE, et al. Photophysical, photochemical and antibacterial photosensitizing properties of a novel octacationic Zn(II)-phthalocyanine. Photochem Photobiol Sci 2002; 1: 641-8.

[87] Bakalova R, Ohba H, Zhelev Z, et al. Quantum Dot anti-CD Conjugates: Are they potential photosensitizers or potentiators of classical photosensitizing agents in photodynamic therapy of cancer? Nano Lett 2004; 4: 1567-73.

[88] Nombona N, Antunes E, Chidawanyika W, Kelyi P, Tshentu Z, Nyokong T. Synthesis, photophysics and photochemistry of phthalocyanine- $\varepsilon$-polylysine conjugates in the presence of metal nanoparticles against Staphylococcus aureus. J Photochem Photobiol A Chem 2012; 233: 24-33.

[89] Perni S, Prokopovich P, Pratten J, Parkin IP, Wilson M. Nanoparticles: their potential use in antibacterial photodynamic therapy. Photochem Photobiol Sci 2011; 10: 712-20.

[90] Dutta S, Ongarora BG, Li H, Vicente Mda G, Kolli BK, Chang KP. Intracellular targeting specificity of novel phthalocyanines assessed in a host-parasite model for developing potential photodynamic medicine. PLoS ONE 2011; 6: e20786.

[91] Robey R, Steadman K, Polgar O, Bates SE. ABCG2-mediated transport of photosensitizers: potential impact on photodynamic therapy. Cancer Biol Ther 2005; 4: 187-94.

[92] Robey R, Fetsch PA, Polgar O, Dean M, Bates SE. The livestock photosensitizer, phytoporphyrin (phylloerythrin), is a substrate of the ATP-binding cassette transporter ABCG2. Res Vet Sci 2006; 81: 345-9.

[93] Ogino T, Kobuchi H, Munetomo K, et al. Serum-dependent export of protoporphyrin IX by ATP-binding cassette transporter G2 in T24 cells. Mol Cell Biochem 2011; 58: 297-307.

[94] Morgan J, Jackson J, Zheng X, Pandey SK, Pandey RK. Substrate affinity of photosensitizers derived from chlorophyll-a: The ABCG2 transporter affects the phototoxic response of side population stem cell-like cancer cells to photodynamic therapy. Mol Pharm 2010; 7: 1789-804.

[95] Jendzelovský R, Mikes J, Koval' J, et al. Drug efflux transporters, MRP1 and BCRP, affect the outcome of hypericin-mediated photodynamic therapy in HT-29 adenocarcinoma cells. Photochem Photobiol Sci 2009; 8: 1716-23.

[96] Merlin J, Gautier H, Barberi-Heyob M, Teiten MH, Guillemin F. The multidrug resistance modulator SDZ-PSC 833 potentiates the photodynamic activity of chlorin e6 independently of Pglycoprotein in multidrug resistant human breast adenocarcinoma cells. Int J Oncol 2003; 22: 733-9.

[97] Wang E, Casciano CN, Clement RP, Johnson WW. Inhibition of Pglycoprotein transport function by grapefruit juice psoralen. Pharm Res 2001; 18: 432-8.

[98] Adigbli D, Wilson DG, Farooqui N, et al. Photochemical internalisation of chemotherapy potentiates killing of multidrugresistant breast and bladder cancer cells. Br J Cancer 2007; 97: 502-12.

[99] Stermitz F, Lorenz P, Tawara JN, Zenewicz LA, Lewis K. Synergy in a medicinal plant: antimicrobial action of berberine potentiated by 5 '-methoxyhydnocarpin, a multidrug pump inhibitor. Proc Natl Acad Sci USA 2000; 97: 1433-7.

[100] Tegos G, Hamblin MR. Phenothiazinium antimicrobial photosensitizers are substrates of bacterial multidrug resistance pumps. Antimicrob Agents Chemother 2006; 50: 196-203.

[101] Tseng SP, Teng LJ, Chen CT, et al. Toluidine blue O photodynamic inactivation on multidrug-resistant Pseudomonas aeruginosa. Lasers Surg Med 2009; 41: 391-7.

[102] Prates R, Kato IT, Ribeiro MS, Tegos GP, Hamblin MR. Influence of multidrug efflux systems on methylene blue-mediated photodynamic inactivation of Candida albicans. J Antimicrob Chemother 2011; 66: 1525-32.

[103] Vera DMA, Haynes MH, Ball AR, et al. Strategies to potentiate antimicrobial photoinactivation by overcoming resistant phenotypes. Photochem Photobiol 2012; 88: 499-511

[104] Sabatini S, Kaatz GW, Rossolini GM, Brandini D, Fravolini A. From phenothiazine to 3-phenyl-1,4-benzothiazine derivatives as inhibitors of the Staphylococcus aureus NorA multidrug efflux pump. J Med Chem 2008; 51: 4321-30.

[105] Amaral L, Martins M, Viveiros M, Molnar J, Kristiansen JE. Promising therapy of XDR-TB/MDR-TB with thioridazine an inhibitor of bacterial efflux pumps. Curr Drug Targets 2008; 9: 816-9.

[106] Bailey A, Paulsen IT, Piddock LJ. RamA confers multidrug resistance in Salmonella enterica via increased expression of acrB, which is inhibited by chlorpromazine. Antimicrob Agents Chemother 2008; 10: 3604-11.

[107] Tatsumi R, Wachi M. TolC-dependent exclusion of porphyrins in Escherichia coli. J Bacteriol 2008;190: 6228-33.

[108] Fernandez A, Lechardeur D, Derré-Bobillot A, Couvé E, Gaudu P, Gruss A. Two coregulated efflux transporters modulate intracellular heme and protoporphyrin IX availability in Streptococcus agalactiae. PLoS Pathog 2010; 6: e1000860.

[109] Grinholc M, Zawacka-Pankau J, Gwizdek-Wiśniewska A, Bielawski KP. Evaluation of the role of the pharmacological inhibition of Staphylococcus aureus multidrug resistance pumps and the variable levels of the uptake of the sensitizer in the straindependent response of Staphylococcus aureus to PPArg(2)-based photodynamic inactivation. Photochem Photobiol 2010; 86: 111826.

[110] Grkovic S, Brown MH, Skurray RA. Regulation of Bacterial Drug Export Systems. Microbiol Mol Biol Rev 2002; 66: 671-701.

[111] Kisker C, Hinrichs W, Tovar K, Hillen W, Saenger W. The complex formed between tet repressor and tetracycline-mg2+ reveals mechanism of antibiotic resistance. J Mol Biol 1995; 247: 60.

[112] Bohnert JA, Karamian B, Nikaido H. Optimized Nile Red efflux assay of AcrAB-TolC multidrug efflux system shows competition between substrates. Antimicrob Agents Chemother 2010; 54: 3770 5.

[113] Martins M, Viveiros M, Couto I, et al. Identification of efflux pump-mediated multidrug-resistant bacteria by the ethidium bromide-agar cartwheel method. In Vivo 2011; 25: 171-8.

[114] Viveiros M, Rodrigues L, Martins M, et al. Evaluation of efflux activity of bacteria by a semi-automated fluorometric system. Methods Mol Biol 2010; 642: 159-72.

[115] Kalle A, Rizvi A. Inhibition of bacterial multidrug resistance by celecoxib, a cyclooxygenase-2 inhibitor. Antimicrob Agents Chemother 2011; 55: 439-42.

[116] Matsumoto Y, Hayama K, Sakakihara S, et al. Evaluation of multidrug efflux pump inhibitors by a new method using microfluidic channels. PLoS ONE 2011; 6: e18547.

[117] Leitner I, Nemeth J, Feurstein T, et al. The third-generation Pglycoprotein inhibitor tariquidar may overcome bacterial multidrug resistance by increasing intracellular drug concentration. J Antimicrob Chemother 2011; 66: 834-9.

[118] Mahamoud A, Chevalier J, Baitiche M, Adam E, Pagès JM. An alkylaminoquinazoline restores antibiotic activity in Gram-negative resistant isolates. Microbiology 2011; 157: 566-71.

[119] Eliopoulos GM, Moellering RC. Antibiotics in laboratory medicine. In: Lorian V, Ed. Antibiotics in laboratory medicine. Baltimore, MD: Williams \& Wilkins Co. 1991; pp. 432-92.

[120] Kamicker B, Sweeney MT, Kaczmarek F, et al. Bacterial efflux pump inhibitors. Methods Mol Med 2008; 142: 187-200.

[121] Odds F. Synergy, antagonism, and what the chequerboard puts between them. J Antimicrob Chemother 2003; 52: 1.

[122] Ackerman B, Vannier AM, Eudy EB. Analysis of vancomycin time-kill studies with Staphylococcus species by using a curve stripping program to describe the relationship between concentration and pharmacodynamic response. Antimicrob Agents Chemother 1992; 36: 1766-9.

[123] Sharma S, Kumar M, Sharma S, Nargotra A, Koul S, Khan IA. Piperine as an inhibitor of Rv1258c, a putative multidrug efflux pump of Mycobacterium tuberculosis. J Antimicrob Chemother 2010; 65: 1694-701. 
[124] Yin Y, He X, Szewczyk P, Nguyen T, Chang G. Structure of the multidrug transporter EmrD from Escherichia coli. Science 2006; 312: 741-4.

[125] Huang Y, Lemieux MJ, Song J, Auer M, Wang DN. Structure and Mechanism of the Glycerol-3-Phosphate Transporter from Escherichia coli. Science 2003; 301: 616-20.

[126] Aller S, Yu J, Ward A, et al. Structure of P-glycoprotein reveals a molecular basis for poly-specific drug binding. Science 2009; 323:1718-22.

[127] Koronakis V, Sharff A, Koronakis E, Luisi B, Hughes C. Crystal structure of the bacterial membrane protein TolC central to multidrug efflux and protein export. Nature 2000; 405: 914-9.

[128] Sennhauser G, Bukowska MA, Briand C, Grütter MG. Crystal structure of the multidrug exporter MexB from Pseudomonas aeruginosa. J Mol Biol 2009; 389: 134-45.

[129] Phan G, Benabdelhak H, Lascombe MB, et al. Structural and dynamical insights into the opening mechanism of $P$. aeruginosa OprM channel. Structure 2010; 18: 507-17.

[130] Akama H, Matsuura T, Kashiwagi S, et al. Crystal structure of the membrane fusion protein, MexA, of the multidrug transporter in Pseudomonas aeruginosa. J Biol Chem 2004; 279: 25939-42.

[131] Yum S, Xu Y, Piao S, et al. Crystal structure of the periplasmic component of a tripartite macrolide-specific efflux pump. J Mol Biol 2009; 387: 1286-97.

[132] He X, Szewczyk P, Karyakin A, et al. Structure of a cation-bound multidrug and toxic compound extrusion transporter. Nature 2010; 467: 991-4.

[133] Brincat J, Carosati E, Sabatini S, et al. Discovery of novel inhibitors of the NorA multidrug transporter of Staphylococcus aureus. J Med Chem 2011; 54: 354-65.

[134] Medina-Franco1 JL, Martínez-Mayorga K, Bender A, Scior T. Scaffold diversity analysis of compound data sets using an entropybased measure. QSAR Comb Sci 2009, 28, 1551-1560.

[135] Nargotra A, Sharma S, Koul JL, et al. Quantitative structure activity relationship (QSAR) of piperine analogsfor bacterial NorA efflux pump inhibitors. Eur J Med Chem 2009; 44: 4128-35.

[136] Dai Y, Zhang X, Zhang X, Wang H, Lu Z. DFT and GA studies on the QSAR of 2-aryl-5-nitro-1H-indole derivatives as NorA efflux pump inhibitors. J Mol Model 2008;14: 807-12.

[137] Edwards B, Kuckuck FW, Prossnitz ER, Ransom JT, Sklar LA. HTPS flow cytometry: a novel platform for automated high throughput drug discovery and characterization. J Biomol Screen 2001; 6: 83-90.

[138] Winter S, Lovato DM, Khawaja HM, et al. High-throughput screening for daunorubicin-mediated drug resistance identifies mometasone furoate as a novel ABCB1-reversal agent. J Biomol Screen 2008; 13: 185-93.

[139] Ivnitski-Steele I, Larson RS, Lovato DM, et al. High-throughput flow cytometry to detect selective inhibitors of $\mathrm{ABCB} 1, \mathrm{ABCC} 1$, and ABCG2 transporters. Assay Drug Dev Technol 2008; 2: 26376.

[140] Ivnitski-Steele I, Holmes AR, Lamping E, Monk BC, Cannon RD, Sklar LA. Identification of Nile red as a fluorescent substrate of the Candida albicans ATP-binding cassette transporters Cdr1p and $\mathrm{Cdr} 2 \mathrm{p}$ and the major facilitator superfamily transporter Mdrlp. Anal Biochem 2009; 394: 87-91.

[141] Holmes A, Keniya MV, Ivnitski-Steele I, et al. The monoamine oxidase A inhibitor clorgyline is a broad-spectrum inhibitor of fungal $\mathrm{ABC}$ and MFS transporter efflux pump activities which reverses the azole resistance of Candida albicans and Candida glabrata clinical isolates. Antimicrob Agents Chemother 2012; 56: 1508-15.

[142] WHO. World health organization reports highest rates of drugresistant tuberculosis to date. Available at: wwwwhoint/tb/features_archive/drs_factsheetpdf [accessed 10 October 2010] 2008.

[143] da Silva P, Von Groll A, Martin A, Palomino JC. Efflux as a mechanism for drug resistance in Mycobacterium tuberculosis. FEMS Immunol Med Microbiol 2011; 63: 1-9.

[144] Barrett J. MC-207110 Daiichi seiyaku/microcide pharmaceuticals. Curr Opin Investig Drugs 2001; 2: 212-5.

[145] Kern WV, Steinke P, Schumacher A, Schuster S, von Baum H, Bohnert JA. Effect of 1-(1-naphthylmethyl)-piperazine, a novel putative efflux pump inhibitor, on antimicrobial drug susceptibility in clinical isolates of Escherichia coli. J Antimicrob Chemother 2006; 57: 339-43.
[146] Coban AY, Tanniverdi Cayci Y, Erturan Z, Durupinar B. Effects of efflux pump inhibitors phenyl-arginine-beta-naphthylamide and 1(1-naphthylmethyl)-piperazine on the antimicrobial susceptibility of Pseudomonas aeruginosa isolates from cystic fibrosis patients. J Chemother 2009; 21: 592-4.

[147] Chevalier J, Bredin J, Mahamoud A, Malléa M, Barbe J, Pagès JM. Inhibitors of antibiotic efflux in resistant Enterobacter aerogenes and Klebsiella pneumoniae strains. Antimicrob Agents Chemother 2004; 48: 1043-6.

[148] Li B, Yao Q, Pan XC, et al. Artesunate enhances the antibacterial effect of \{beta\}-lactam antibiotics against Escherichia coli by increasing antibiotic accumulation via inhibition of the multidrug efflux pump system AcrAB-TolC. J Antimicrob Chemother 2011; 66: 769-77.

[149] Tegos G. Substrates and Inhibitors of microbial efflux pumps; Redifine the Role of Plant Antimicrobials. In: Mahendra Rai CMC, Ed. Naturally occurring bioactive compounds: a new and safe alternative for control of pests and microbial diseases. Cambridge: Cambridge University Press; 2006.

[150] Garvey M, Rahman MM, Gibbons S, Piddock LJ. Medicinal plant extracts with efflux inhibitory activity against Gram-negative bacteria. Int J Antimicrob Agents 2011; 37: 145-51.

[151] Zhou X, Jia F, Liu X, Wang Y. Total Alkaloids of sophorea alopecuroides-induced down-regulation of acrab-tolc efflux pump reverses susceptibility to ciprofloxacin in clinical multidrug resistant escherichia coli isolates. Phytother Res 2012; 26: 1637-43.

[152] Kino $\mathrm{T}$, Hatanaka $\mathrm{H}$, Hashimoto $\mathrm{M}$, et al. FK-506, a novel immunosuppressant isolated from a Streptomyces. I. Fermentation, isolation, and physico-chemical and biological characteristics. J Antibiot (Tokyo) 1987; 40: 1249-55.

[153] Tanabe K, Lamping E, Adachi K, et al. Inhibition of fungal ABC transporters by unnarmicin $\mathrm{A}$ and unnarmicin $\mathrm{C}$, novel cyclic peptides from marine bacterium. Biochem Biophys Res Commun 2007; 364: 990-5.

[154] Oku N, Kawabata K, Adachi K, Katsuta A, Shizuri Y. Unnarmicins $\mathrm{A}$ and $\mathrm{C}$, new antibacterial depsipeptides produced by marine bacterium Photobacterium sp. MBIC06485. J Antibiot (Tokyo) 2008; 61: 11-7.

[155] Digirolamo J, Li XC, Jacob MR, Clark AM, Ferreira D. Reversal of fluconazole resistance by sulfated sterols from the marine sponge Topsentia sp. J Nat Prod 2009; 72: 1524-8.

[156] Hiraga K, Yamamoto S, Fukuda H, Hamanaka N, Oda K. Enniatin has a new function as an inhibitor of Pdr5p, one of the ABC transporters in Saccharomyces cerevisiae. Biochem Biophys Res Commun 2005; 328: 1119-25.

[157] Lee M, Galazzo J, Staley AL, et al. Microbial fermentation-derived inhibitors of efflux-pump-mediated drug resistance. Farmaco 2001; 56: $81-5$.

[158] Tegos G, Masago K, Aziz F, Higginbotham A, Stermitz FR, Hamblin MR. Inhibitors of bacterial multidrug efflux pumps potentiate antimicrobial photoinactivation. Antimicrob Agents Chemother 2008; 52(9): 3202-9.

[159] Klyachko K, Schuldiner S, Neyfakh AA. Mutations affecting substrate specificity of the Bacillus subtilis multidrug transporter BMR J Bacteriol 1997; 179: 2189-93.

[160] Ahmed M, Borsch C, Neyfakh AA, Schuldner S. Mutants of Bacillus subtilis multidrug transporter Bmr with altered sensitivity to the antihypertensive alkaloid reserpine. J Biol Chem 1993; 268: 11086-9.

[161] Garvey M, Piddock LJ. The efflux pump inhibitor reserpine selects multidrug-resistant Streptococcus pneumoniae strains that overexpress the $\mathrm{ABC}$ transporters PatA and PatB. Antimicrob Agents Chemother 2008; 52: 1677-85.

[162] Ball A, Casadei G, Samosorn S, et al. Conjugating berberine to a multidrug efflux pump inhibitor creates an effective antimicrobial. ACS Chem Biol 2006; 1: 594-600.

[163] Samosorn S, Tanwirat B, Muhamad N, et al. Antibacterial activity of berberine-NorA pump inhibitor hybrids with a methylene ether linking group. Bioorg Med Chem 2009; 17: 3866-72.

[164] Tomkiewicz D, Casadei G, Larkins-Ford J, et al. Berberine-INF55 (5-nitro-2-phenylindole) hybrid antimicrobials: effects of varying the relative orientation of the berberine and INF55 components. Antimicrob Agents Chemother 2010; 54: 3219-24.

[165] Martinez J, Sánchez MB, Martínez-Solano L, et al. Functional role of bacterial multidrug efflux pumps in microbial natural ecosystems. FEMS Microbiol Rev 2009; 33: 430-49. 
[166] Apidianakis Y, Mindrinos MN, Xiao W, et al. Involvement of skeletal muscle gene regulatory network in susceptibility to wound infection following trauma. PLoS ONE 2007; 2: e1356.

[167] Apidianakis $\mathrm{Y}$, Que $\mathrm{YA}, \mathrm{Xu} \mathrm{W}$, et al. Down-regulation of glutatione S-transferase alpha 4 (hGSTA4) in the muscle of thermally injured patients is indicative of susceptibility to bacterial infection. FASEB J 2012; 26: 730-7.

[168] Fuchs B, O'Brien E, Khoury JB, Mylonakis E. Methods for using Galleria mellonella as a model host to study fungal pathogenesis. Virulence 2010; 1: 475-82.

[169] Sánchez P, Linares JF, Ruiz-Díez B, et al. Fitness of in vitro selected Pseudomonas aeruginosa nalB and $n f \times B$ multidrug resistant mutants. J Antimicrob Chemother 2002; 50: 657-64.

[170] Olivares J, Alvarez-Ortega C, Linares JF, Rojo F, Köhler T, Martínez JL. Overproduction of the multidrug efflux pump MexEF-OprN does not impair Pseudomonas aeruginosa fitness in competition tests, but produces specific changes in bacterial regulatory networks. Environ Microbiol 2012; 14: 1968-8.

[171] O'Quinn A, Wiegand EM, Jeddeloh JA. Burkholderia pseudomallei kills the nematode Caenorhabditis elegans using an endotoxinmediated paralysis. Cell Microbiol 2001; 3: 381-93.

[172] Bialek S, Lavigne JP, Chevalier J, et al. Membrane efflux and influx modulate both multidrug resistance and virulence of Klebsiella pneumoniae in a Caenorhabditis elegans model. Antimicrob Agents Chemother 2010; 54: 4373-8.

[173] Maeda T, García-Contreras R, Pu M, et al. Quorum quenching quandary: resistance to antivirulence compounds. ISME J 2012; 6: 493-501.

[174] Bailey A, Ivens A, Kingsley R, Cottell JL, Wain J, Piddock LJ. RamA, a member of the AraC/XylS family, influences both virulence and efflux in Salmonella enterica serovar Typhimurium. J Bacteriol 2010;192:1607-16.

[175] Thakur J, Arthanari H, Yang F, et al. A nuclear receptor-like pathway regulating multidrug resistance in fungi. Nature 2008; 452: 604-9.

[176] Ahmad S, Hunter L, Qin A, Mann BJ, van Hoek ML. Azithromycin effectiveness against intracellular infections of Francisella. BMC Microbiol 2010;10:123.

[177] Salunkhe P, Smart CH, Morgan JA, et al. A cystic fibrosis epidemic strain of Pseudomonas aeruginosa displays enhanced virulence and antimicrobial resistance. J Bacteriol 2005; 187: 490820 .

[178] Adams K, Takaki K, Connolly LE, et al. Drug tolerance in replicating mycobacteria mediated by a macrophage-induced efflux mechanism. Cell 2011; 145: 39-53.

[179] Mirza Z, Kumar A, Kalia NP, Zargar A, Khan IA. Piperine as an inhibitor of the MdeA efflux pump of Staphylococcus aureus. J Med Microbiol 2011; 60: 1472-8.

[180] Sánchez-Gómez S, Japelj B, Jerala R, et al. Structural features governing the activity of lactoferricin-derived peptides that act in synergy with antibiotics against Pseudomonas aeruginosa in vitro and in vivo. Antimicrob Agents Chemother 2011; 55: 218-28.

[181] Hayama K, Ishibashi H, Ishijima SA, et al. A d-octapeptide drug efflux pump inhibitor acts synergistically with azoles in a murine oral candidiasis infection model. FEMS Microbiol Lett 2012; 328: 130-7.

[182] Hashimoto M, Prates RA, Kato IT, Núñez SC, Courrol LC, Ribeiro MS. Antimicrobial photodynamic therapy on drug-resistant pseudomonas aeruginosa-induced infection. An in vivo study. Photochem Photobiol 2012; 88: 590-5.

[183] Ding Y, Onodera Y, Lee JC, Hooper DC. NorB, an efflux pump in Staphylococcus aureus strain MW2, contributes to bacterial fitness in abscesses. J Bacteriol 2008; 190: 7123-9.

[184] Pérez A, Poza M, Fernández A, et al. Involvement of the AcrABTolC efflux pump in the resistance, fitness and virulence of Enterobacter cloacae. Antimicrob Agents Chemother 2012; 56: 2084-90

[185] Platz G, Bublitz DC, Mena P, Benach JL, Furie MB, Thanassi DG. A tolC mutant of Francisella tularensis is hypercytotoxic compared to the wild type and elicits increased proinflammatory responses from host cells. Infect Immun 2010; 78: 1022-31.

[186] Gil H, Platz GJ, Forestal CA, et al. Deletion of TolC orthologs in Francisella tularensis identifies roles in multidrug resistance and virulence. Proc Natl Acad Sci USA 2006; 103: 12897-902.

[187] Kadzhaev K, Zingmark C, Golovliov I, et al. Identification of genes contributing to the virulence of Francisella tularensis SCHU
S4 in a mouse intradermal infection model. PLoS ONE 2009; 4(5): e5463.

[188] Fiamegos Y, Kastritis PL, Exarchou V, et al. Antimicrobial and efflux pump inhibitory activity of caffeoylquinic acids from Artemisia absinthium against gram-positive pathogenic bacteria. PLoS ONE 2011; 6: e18127.

[189] Belofsky G, Carreno R, Lewis K, Ball A, Casadei G, Tegos GP. Metabolites of the "smoke tree", Dalea spinosa, potentiate antibiotic activity against multidrug-resistant Staphylococcus aureus. J Nat Prod 2006; 69: 261-4.

[190] Michalet S, Cartier G, David B, et al. N-caffeoylphenalkylamide derivatives as bacterial efflux pump inhibitors. Bioorg Med Chem Lett 2007; 17: 1755-8.

[191] Belofsky G, Percivil D, Lewis K, Tegos G, Ekart J. Phenolic Metabolites of Dalea versicolor that Enhance Antibiotic Activity Against Multi-Drug Resistant Bacteria. J Nat Prod 2004; 67: 481-4.

[192] Abulrob AN, Suller MTE, Gumbleton M, Simons C, Russell A. Identification and biological evaluation of grapefruit oil components as potential novel efflux pump modulators in methicillin-resistant Staphylococcus aureus bacterial strains. Phytochemistry 2004; 65: 3021-7.

[193] Fazly Bazzaz BS, Iranshahi M, Naderinasa M, Hajian S, Sabeti Z, Masumi E. Evaluation of the effects of galbanic acid from Ferula szowitsiana and conferol from F. badrakema, as modulators of multi-drug resistance in clinical isolates of Escherichia coli and Staphylococcus aureus. Res Pharm Sci 2010; 5: 21-8.

[194] Fujita M, Shiota S, Kuroda T, et al. Remarkable synergies between baicalein and tetracycline, and baicalein and beta-lactams against methicillin-resistant Staphylococcus aureus. Microbiol Immunol 2005; 49: 391-6.

[195] Stermitz F, Scriven LN, Tegos G, Lewis K. Two flavonols from Artemisa annua which potentiate the activity of berberine and norfloxacin against a resistant strain of Staphylococcus aureus. Planta Med 2002; 68: 1140-1.

[196] Falcão-Silva V, Silva DA, Souza Mde F, Siqueira-Junior JP. Modulation of drug resistance in Staphylococcus aureus by a kaempferol glycoside from Herissantia tiubae (Malvaceae). Phytother Res 2009; 10: 1367-70.

[197] Stermitz F, Tawara-Matsuda J, Lorenz P, Mueller P, Zenewicz L, Lewis K. 5-0-Methoxyhydnocarpin-D and pheophorbide A: Berberis species components that potentiate berberine growth inhibition of resistant Staphylococcus aureus. J Nat Prod 2000; 63: 1146-9.

[198] Morel C, Stermitz F, Tegos G, Lewis K. Isoflavones as potentiators of antibacterial activity. J Agric Food Chem 2003; 51: 5677-9.

[199] Gibbons S, Moser E, Kaatz GW. Catechin gallates inhibit multidrug resistance (MDR) in Staphylococcus aureus. Planta Med 2004; 70: 1240-2.

[200] Sudano Roccaro A, Blanco AR, Giuliano F, Rusciano D, Enea V. Epigallocatechin-gallate enhances the activity of tetracycline in staphylococci by inhibiting its efflux from bacterial cells. Antimicrob Agents Chemother 2004; 48: 1968-73.

[201] Oluwatuyi M, Kaatz GW, Gibbons S. Antibacterial and resistance modifying activity of Rosmarinus officinalis. Phytochemistry 2004; 65: 3249-54.

[202] Smith E, Kaatz GW, Seo SM, Wareham N, Williamson EM, Gibbons S. The phenolic diterpene totarol inhibits multidrug efflux pump activity in Staphylococcus aureus. Antimicrob Agents Chemother 2007; 51: 4480-3.

[203] Gibbons S, Oluwatuyi M, Veitch NC, Gray AI. Bacterial resistance modifying agents from Lycopus europaeus. Phytochemistry 2003; 62: 83-7.

[204] Smith ECJ, Williamson EM, Wareham N, Kaatz GW, Gibbons S Antibacterials and modulators of bacterial resistance from the immature cones of Chamaecyparis lawsoniana. Phytochemistry 2007; 68: 210-7.

[205] Martins A, Vasas A, Viveiros M, Molnár J, Hohmann J, Amaral L. Antibacterial properties of compounds isolated from Carpobrotus edulis. Int J Antimicrob Agents 2011; 37: 438-44.

[206] Chérigo L, Pereda-Miranda R, Gibbons S. Bacterial resistance modifying tetrasaccharide agents from Ipomoea murucoides. Phytochemistry 2009; 70: 222-7.

[207] Pereda-Miranda R, Kaatz GW, Gibbons S. Polyacylated oligosaccharides from medicinal Mexican morning glory species as antibacterials and inhibitors of multidrug resistance in Staphylococcus aureus. J Nat Prod 2006; 69: 406-9. 
[208] Stermitz F, Halligan KM, Morel C, Tegos GP, Lewis K. Polyacylated neohesperidosides From Geranium caespitosum: bacterial multidrug resistance pump inhibitors. Bioorg Med Chem Lett 2003; 13: 1915-8.

[209] Chérigo L, Pereda-Miranda R, Fragoso-Serrano M, Jacobo-Herrera N, Kaatz GW, Gibbons S. Inhibitors of bacterial multidrug efflux pumps from the resin glycosides of Ipomoea murucoides. J Nat Prod 2008; 71: 1037-45.

[210] Khan IA, Mirza ZM, Kumar A, Verma V, Qazi GN. Piperine, a phytochemical potentiator of ciprofloxacin against Staphylococcus aureus. Antimicrob Agents Chemother 2006; 50: 810-2.

[211] Marquez B. Bacterial efflux systems and efflux pumps inhibitors. Biochimie 2005; 87: 1137-47.

[212] Mohtar M, Johari SA, Li AR, Isa MM, Mustafa S, Ali AM, Basri DF. Inhibitory and resistance-modifying potential of plant-based alkaloids against methicillin-resistant Staphylococcus aureus (MRSA). Curr Microbiol 2009; 59: 181-6.

[213] Musumeci R, Speciale A, Costanzo R, et al. Berberis aetnensis C. Presl. extracts: antimicrobial properties and interaction with ciprofloxacin. Int J Antimicrob Agents 2003; 22: 48-5.

[214] Stavri M, Piddock LJV, Gibbons S. Bacterial efflux pump inhibitors from natural sources. J Antimicrob Chemother 2007; 59: 1247-60.

[215] Ponnusamy K, Ramasamy M, Savarimuthu I, Paulraj MG. Indirubin potentiates ciprofloxacin activity in the NorA efflux pump of Staphylococcus aureus. Scand J Infect Dis 2010; 42: 5005.
[216] Lechner D, Gibbons S. Bucar F. Modulation of isoniazid susceptibility by flavonoids in Mycobacterium. Phytochem Lett 2008; 1: 71-5.

[217] Lechner D, Gibbons S, Bucar F. Plant phenolic compounds as ethidium bromide efflux inhibitors in Mycobacterium smegmatis. J Antimicrob Chemother 2008; 62: 345-8.

[218] Mossa JS, El Feraly FS, Muhammad I. Antimycobacterial constituents from Juniperus procera, Ferula communis and Plumbago zeylanica and their in vitro synergistic activity with isonicotinic acid hydrazide. Phytother Res 2004; 18: 934-7

[219] Jin J, Zhang JY, Guo N, et al. Farnesol, a potential efflux pump inhibitor in Mycobacterium smegmatis. Molecules 2010; 15: 775062.

[220] Lechner D, Gibbons S, Jachak S, Srivastava A, Bucar F. Curcuminoids as efflux pump inhibitors (EPIs) in Mycobacterium smegmatis mc2155. In: Skaltsounis L, Magiatis P Eds. Book of Abstracts-7th Joint Meeting of GA, AFERP, ASP, PSI \& SIF; 2008; Athens, Greece; 2008; p. 12.

[221] Piddock L, Garvey MI, Rahman MM, Gibbons S. Natural and synthetic compounds such as trimethoprim behave as inhibitors of efflux in Gram-negative bacteria. J Antimicrob Chemother 2010; 65: 1215-23.

[222] Pagès J, Dimarcq JL, Quenin S, Hetru C. Thanatin activity on multidrug resistant clinical isolates of Enterobacter aerogenes and Klebsiella pneumoniae. Int J Antimicrob Agents 2003; 22: 265-9.

[223] Chusri S, Villanueva I, Voravuthikunchai SP, Davies J. Enhancing antibiotic activity: a strategy to control Acinetobacter infections. J Antimicrob Chemother 2009; 64: 1203-11.

(C) Kourtesi et al.; Licensee Bentham Open.

This is an open access article licensed under the terms of the Creative Commons Attribution Non-Commercial License (http://creativecommons.org/licenses/ by-nc/3.0/) which permits unrestricted, non-commercial use, distribution and reproduction in any medium, provided the work is properly cited. 